\title{
Evaluation of antibacterial, angiogenic, and osteogenic activities of green synthesized gap- bridging copper-doped nanocomposite coatings
}

This article was published in the following Dove Press journal:

International Journal of Nanomedicine

II October 2017

Number of times this article has been viewed

\section{Dan Huang' \\ Kena Ma ${ }^{1,2}$ \\ Xinjie Cai ${ }^{1,2}$ \\ Xu Yang ${ }^{3}$ \\ Yinghui $\mathrm{Hu}^{\prime}$ \\ Pin Huang' \\ Fushi Wang' \\ Tao Jiang ${ }^{1,2}$ \\ Yining Wang ${ }^{1,2}$}

'The State Key Laboratory Breeding Base of Basic Science of Stomatology (Hubei- MOST) \& Key Laboratory of Oral Biomedicine Ministry of Education, School \& Hospital of Stomatology, Wuhan University, ${ }^{2}$ Department of Prosthodontics, Hospital of Stomatology, Wuhan University, Wuhan, China;

${ }^{3}$ Department of Oral Biology, School of Dental Medicine, University of Pittsburgh, Pittsburgh, PA, USA
Correspondence: Tao Jiang; Yining Wang Department of Prosthodontics, Hospital of Stomatology, Wuhan University, Luoyu Road 237, Hongshan District, Wuhan, 430079, China

Tel +862787686318

Fax +86 2787873260

Email jiangtao2006@whu.edu.cn; wang.yn@whu.edu.cn

\begin{abstract}
Titanium (Ti) and its alloys have been widely used in clinics for years. However, their bio-inert surface challenges application in patients with compromised surgical conditions. Numerous studies were conducted to modify the surface topography and chemical composition of Ti substrates, for the purpose of obtaining antibacterial, angiogenic, and osteogenic activities. In this study, using green electrophoretic deposition method, we fabricated gap-bridging chitosan-gelatin (CSG) nanocomposite coatings incorporated with different amounts of copper $(\mathrm{Cu} ; 0.01,0.1,1$, and $10 \mathrm{mM}$ for $\mathrm{Cu}$ I, II, III, and IV groups, respectively) on the Ti substrates. Physicochemical characterization of these coatings confirmed that $\mathrm{Cu}$ ions were successfully deposited into the coatings in a metallic status. After rehydration, the coatings swelled by $850 \%$ in weight. Mechanical tests verified the excellent tensile bond strength between Ti substrates and deposited coatings. All Cu-containing CSG coatings showed antibacterial property against both Gram-negative Escherichia coli and Gram-positive Staphylococcus aureus. The antibacterial property was positively correlated with the $\mathrm{Cu}$ concentration. In vitro cytocompatibility evaluation demonstrated that activities of bone marrow stromal cells were not impaired on $\mathrm{Cu}$-doped coatings except for the $\mathrm{Cu}$ IV group. Moreover, enhanced angiogenic and osteogenic activities were observed on $\mathrm{Cu}$ II and $\mathrm{Cu}$ III groups. Overall, our results suggested that $\mathrm{Cu}$-doped CSG nanocomposite coating is a promising candidate to functionalize Ti materials with antibacterial, angiogenic, and osteogenic properties.
\end{abstract}

Keywords: copper, gap-bridging, antibacterial, angiogenic, osteogenic

\section{Introduction}

Since the pioneering work of Ödman et al, ${ }^{1}$ titanium (Ti) and its alloys have been increasingly used in clinics for biomedical application because of their excellentphysicochemical properties and superior biocompatibility., ${ }^{2,3}$ However, clinicians are still confronting challenges like biomaterial-associated infections (BAIs) and poor bone osseointegration, ${ }^{4,5}$ owing to the lack of antibacterial, osteogenic, and angiogenic activities of bare Ti materials.

A well-known approach to functionalize the Ti surface is to incorporate antibiotics and various growth factors, such as gentamicin, bone morphogenetic protein-2, and vascular endothelial growth factor (VEGF). ${ }^{6-8}$ However, antibiotics are unstable and can be easily decomposed, ${ }^{9}$ growth factors are generally expensive, and overdose might cause adverse effects. Due to these drawbacks, their clinical application is limited and alternative methods are required. Recently, more and more research projects aiming to improve the performance of Ti-based materials have focused on surface loading of inorganic metal ions, which showed stable and durable biological properties. ${ }^{10-12}$ 
Among them, copper $(\mathrm{Cu})$ has drawn our attention for its balanced property between antibacterial activity and cytotoxicity. ${ }^{13}$ Similar to many other noble metals, $\mathrm{Cu}$ is known to inhibit bacterial viability by denaturing the respiratory enzyme or destroying cell membrane. ${ }^{14}$ Moreover, it has demonstrated outstanding ability to stimulate angiogenic and osteogenic differentiation of stem cells. ${ }^{15-19}$ More precisely, $\mathrm{Cu}$ was thought to promote angiogenesis by inducing the expression of hypoxia inducible factor (HIF-1 $\alpha$ ) and VEGF, therefore artificially mimicking hypoxia, which played a critical role in blood vessel formation. In the work of Yu et a ${ }^{16}$ and Burghardt et al, ${ }^{20} \mathrm{Cu}$-bearing surfaces manifested considerable antibacterial, osteogenic, and angiogenic properties. Inspired by these advantages of $\mathrm{Cu}$, we attempted to introduce this inorganic element in the surface functionalization of biomedical Ti-based materials.

There is a variety of strategies to functionalize the surface of Ti substrates, including plasma immersion ion implantation, ${ }^{16}$ hydrothermal method, ${ }^{21}$ magnetron cosputtering process, ${ }^{22}$ and electrophoretic deposition (EPD). ${ }^{23,24}$ In our previous studies, EPD technique was routinely used to prepare organic chitosan-gelatin (CSG) nanosphere coating on Ti substrates. ${ }^{25-27}$ It showed favorable mechanical property, swelling ability, biodegradability, and biocompatibility. Moreover, the mild coating condition (room temperature, water solution) and convenient protocol make it a promising candidate for further loading of functional agents like metal ions. ${ }^{27,28}$

In this study, Cu-doped CSG nanocomposite coatings were successfully fabricated by an environmentally friendly EPD process (green chemistry) without the use of harsh, toxic, and costly chemicals. ${ }^{29-31}$ As far as we know, this is the first time $\mathrm{Cu}$-doped organic-inorganic coatings have been synthesized to functionalize the Ti surface. The antibacterial ability of the coatings against Gram-negative Escherichia coli (E. coli) and Gram-positive Staphylococcus aureus (S. aureus) was examined. Furthermore, rat bone marrow mesenchymal stromal cells were used to investigate the cytocompatibility, angiogenic, and osteogenic potential of the coatings. This study may highlight the potential use of the $\mathrm{Cu}$-doped CSG coatings in clinical application.

\section{Materials and methods}

\section{Materials}

Commercially pure Ti disks $(15 \mathrm{~mm}$ in diameter, $1 \mathrm{~mm}$ thick, grade 2) were provided by Baoji Titanium Industry Co, Ltd (China) and pretreated according to our previous study. ${ }^{25}$ Briefly, the disks were sandblasted with large grits and acid etched with $\mathrm{HCl} / \mathrm{H}_{2} \mathrm{SO}_{4}$ for 30 minutes at $60^{\circ} \mathrm{C}$, and then ultrasonically cleaned in acetone, ethanol, and Milli-Q water sequentially. Chitosan (MW 1,000,000 Da) with a deacetylation degree $>95 \%$ was obtained from Golden-Shell Biochemical Co, Ltd (Zhejiang, China). Gelatin (type A, G1890) derived from acid-cured tissue was supplied by Sigma Aldrich (St Louis, MO, USA). All the other chemical reagents were local products of analytical grade.

\section{Preparation of electrophoretic solutions and EPD process}

The CSG solution was prepared as in our previous study. ${ }^{25}$ In brief, $0.6 \mathrm{~g}$ chitosan was dissolved in $80 \mathrm{~mL} 0.04 \mathrm{M}$ hydrochloric acid with magnetic stirring at room temperature for 2 hours. The $\mathrm{pH}$ value was adjusted to 4.0 using $0.5 \mathrm{M} \mathrm{NaOH}$; then, $1.4 \mathrm{~g}$ gelatin was dissolved into the chitosan solution at $60^{\circ} \mathrm{C}$ for 1.5 hours, and the total volume of the solution was brought to $100 \mathrm{~mL}$ with Milli-Q water. $\mathrm{Cu}$ chloride was added into the CSG solution to obtain the final electrophoretic solution. In total, five groups were made, namely CSG, Cu I, $\mathrm{Cu}$ II, $\mathrm{Cu}$ III, and $\mathrm{Cu}$ IV, with $\mathrm{Cu}$ concentrations of $0,0.01$, $0.1,1$, and $10 \mathrm{mM}$ (Table 1).

During the process of EPD, the Ti substrate was used as the cathode with a parallel platinum plate as the anode. The distance between the two electrodes was $50 \mathrm{~mm}$. EPD was carried out using a direct current power supply (model 6614C; Agilent Technologies, Santa Clara, CA, USA) by keeping the current at $15 \mathrm{~mA}$ for 2 minutes. After the deposition, the coated $\mathrm{Ti}$ was disconnected from the power supply, removed from the electrophoretic solutions, rinsed gently with Milli-Q water, and then air-dried overnight for future study.

\section{Characterization of the deposited coatings \\ Surface topography and physicochemical characterization}

Immediately after EPD, the freshly deposited coatings were diluted with Milli-Q water and then examined by transmission electron microscopy (TEM; JEOL JEM 2100; JEOL Ltd, Tokyo, Japan) to observe the contents. Optical photographs of the fresh coatings were taken using a camera

Table I Concentration of chitosan, gelatin, and copper chloride in the electrophoretic deposition solution

\begin{tabular}{llllll}
\hline Concentration & CSG & Cu I & Cu II & Cu III & Cu IV \\
\hline Chitosan $(g / 100 ~ m L)$ & 0.6 & 0.6 & 0.6 & 0.6 & 0.6 \\
Gelatin $(g / 100 \mathrm{~mL})$ & 1.4 & 1.4 & 1.4 & 1.4 & 1.4 \\
$\mathrm{CuCl}_{2}(\mathrm{mM})$ & 0 & $0.0 \mathrm{I}$ & 0.1 & $\mathrm{I}$ & 10 \\
\hline
\end{tabular}

Abbreviation: CSG, chitosan-gelatin. 
(Nikon 90; Nikon Corporation, Tokyo, Japan). In addition, the coatings were visualized by fluorescence microscopy (Nikon TE-2000). After being air-dried, optical images of the coatings were obtained again and the coatings were observed using field emission scanning electron microscopy (FESEM; Carl Zeiss Meditec AG, Jena, Germany). For qualitative elemental analysis of the coatings, energy-dispersive X-ray spectrometry (EDS; Quanta-200; FEI, Eindhoven, the Netherlands) was used. Surface chemistry was investigated with attenuated total reflection Fourier transform infrared spectroscopy (FTIR; Thermo Nicolet 5700; Thermo Fisher Scientific, Waltham, MA, USA). In addition, the chemical state of $\mathrm{Cu}$ in the coatings was studied by X-ray photoelectron spectroscopy (XPS; Kratos XSAM 800; Kratos Analytical, Manchester, UK).

\section{$\mathrm{Cu}$ entrapment and release assay}

To investigate the total amount of $\mathrm{Cu}$ entrapped in the coatings, fresh coatings were collected and diluted to $10 \mathrm{~mL}$ after being treated with hydrogen nitrate $\left(\mathrm{HNO}_{3}\right)$; then, the samples were analyzed for concentration of $\mathrm{Cu}$ using an atomic absorption spectrophotometer (AAS; ContrAA 700; Analytik Jena AG, Germany). Each group had three disks for the test.

For the $\mathrm{Cu}$ release assay, each sample was soaked in $5 \mathrm{~mL}$ phosphate-buffered saline (PBS) at $37^{\circ} \mathrm{C}$ without agitation. At 6 hours, 12 hours, 24 hours, 3 days, 7 days, 14 days, 21 days, and 28 days, all the immersion solution was extracted, and replaced by fresh PBS. The extracted solution was treated with $\mathrm{HNO}_{3}$ and analyzed by AAS for the concentration of $\mathrm{Cu}$.

In order to observe the morphology of the $\mathrm{Cu}$ compounds released from the coatings, the dried coatings were immersed in $5 \mathrm{~mL}$ Milli-Q water for 24 hours, and the released suspension was diluted with Milli-Q water followed by TEM analysis.

\section{Swelling ratio}

Swelling characteristic of the coatings was determined by immersing the coated Ti substrates into PBS solution for 2, $10,20,30,40,50,60,90,120$ minutes. The swelling ratio was determined as: $\mathrm{SR}=\left(\mathrm{W}_{2}-\mathrm{W}_{1}\right) /\left(\mathrm{W}_{1}-\mathrm{W}_{0}\right)$, where $\mathrm{SR}$ is the swelling ratio of the coating, $\mathrm{W}_{0}$ is the weight of the pure Ti disk, $\mathrm{W}_{1}$ is the dry weight of the coated disk, and $\mathrm{W}_{2}$ is the wet weight of the coated disk after immersion in PBS at a certain time point.

\section{Degradation rate}

Degradation of the coatings was performed in sterilized PBS ( $\mathrm{pH} 7.4$ ) containing $1.5 \mu \mathrm{g} \mathrm{mL} \mathrm{m}^{-1}$ lysozyme at $37^{\circ} \mathrm{C}$. After incubation at predetermined time intervals ( 6 hours, 12 hours, 24 hours, 3 days, 7 days, 14 days, 21 days, and 28 days), the samples were removed from the solution, rinsed thoroughly with Milli-Q water, and dried in vacuum for 3 days at room temperature. After measuring the weight, the same disks were put back in degradation solution. The dry weight of each pure Ti disk and coated disk was measured at the start of the assay $\left(\mathrm{W}_{1}, \mathrm{~W}_{2}\right)$ and at the specific time point $\left(\mathrm{W}_{3}\right)$. The degradation rate of the coatings in vitro was expressed as the percentage mass loss (D), which was calculated as: $\mathrm{D}=\left(\mathrm{W}_{2}-\mathrm{W}_{3}\right) /\left(\mathrm{W}_{2}-\mathrm{W}_{1}\right)$.

\section{Mechanical property}

In order to investigate the interface between the coatings and Ti substrates, the shear and tensile bond strength were examined according to our previous study. ${ }^{32}$ Briefly, the coating surface was made to adhere to another Ti plate $\left(20 \times 10 \times 1 \mathrm{~mm}^{3}\right)$ or stainless steel studs $(10 \mathrm{~mm}$ in diameter, $15 \mathrm{~mm}$ thick) using instant gel adhesive (Loctite 454; Henkel Loctite, Düsseldorf, Germany), and cured for 24 hours at ambient temperature. The samples were vertically fixed at the crosshead of the electrical mechanical Instron Model 4465 load frame (Instron Corporation, Norwood, MA, USA) and the long axis of the test samples coincided with the direction of applied forces. The mechanical tests were conducted at a constant displacement of $0.50 \mathrm{~mm}$ per minute until failure was reached, which was evidenced by a drop in load.

\section{In vitro antibacterial study Observation of the bacteria by FESEM}

E. coli (ATCC 25922) and S. aureus (ATCC 25923) were used to assess the antibacterial effect of various samples. Before assay, E. coli and $S$. aureus were cultured in LuriaBertani and tryptic soy broth medium at $37^{\circ} \mathrm{C}$ on a shaker bed at $200 \mathrm{rpm}$ for 6-12 hours, and the concentration was adjusted to $10^{5}-10^{6}$ colony-forming units $\mathrm{mL}^{-1}$. For the FESEM examination, the specimens were cultured with $2 \mathrm{~mL}$ bacterial suspension for 6 hours, and the samples were removed from the medium, fixed overnight at $4^{\circ} \mathrm{C}$, dehydrated through a series of ethanol $(30,50,75,90,95$, and $100 \mathrm{v} / \mathrm{v} \%)$, then gold sputtered in vacuum before observation.

\section{Live/Dead staining}

In the Live/Dead staining assay, the bacterial solution, which was cultured with the samples for 6 hours, was stained with SYTO 9 and propidium iodide dyes according to the protocol of the Live/Dead BacLight Bacterial Viability Kits (L7012; Thermo Fisher Scientific) and immediately observed under fluorescence microscopy (Nikon TE-2000). In addition, the 
number of live and dead bacterial cells per image was analyzed using ImageJ software (National Institutes of Health, Rockville, MD, USA).

\section{Quantitative measurements of antibacterial property}

To quantify the antibacterial ability of the samples, the specimens were incubated with bacterial suspension at $37^{\circ} \mathrm{C}$ for 6 hours; then, the culture medium was diluted and the number of viable bacteria was counted by spread plate method. At the same time, bacteria that adhered on the sample surface were collected by mild ultrasonication in $1 \mathrm{~mL}$ culture medium, and counted by the same method. The antibacterial rates on surface and medium were calculated according to the following formulas: 1) antibacterial rate for adherent bacteria on the sample: $\mathrm{Ra}=(\mathrm{A}-\mathrm{B}) / \mathrm{A} \times 100 \%$ and 2$)$ antibacterial rate for planktonic bacteria in the culture medium: $\mathrm{Rp}=(\mathrm{C}-\mathrm{D}) / \mathrm{C} \times 100 \% .{ }^{33} \mathrm{~A}$ represents the average number of bacteria adhered on the CSG coatings, $\mathrm{B}$ is the average number of bacteria adhered on the $\mathrm{Cu}$-doped coatings, $\mathrm{C}$ is the average number of viable bacteria in the culture medium of the CSG group, and D is the average number of viable bacteria in the culture medium of $\mathrm{Cu}$-containing groups.

\section{Leakage of protein from bacteria}

Similar to the antibacterial test, samples were cocultured with bacterial suspension at $37^{\circ} \mathrm{C}$ for 6 hours. The supernatant $(1 \mathrm{~mL})$ was collected by centrifugation and frozen at $-20^{\circ} \mathrm{C}$ immediately. The concentration of proteins was determined by bicinchoninic acid (BCA) protein assay kit (23235; Thermo Fisher Scientific).

\section{In vitro cellular study}

\section{Culture of rat bone marrow stromal cells (BMSCs)}

BMSCs were harvested from 6-week-old male Wistar rats according to established procedures. All experimental protocols of animals in this study were approved by the Animal Care and Experiment Committee of Wuhan University, and followed the Guide for the Care and Use of Laboratory Animals of Wuhan University. In brief, after cutting off both ends of rat femurs at the epiphysis, the bone marrow was quickly rinsed out with alpha minimum essential medium ( $\alpha$-MEM; SH30265; Hyclone, Logan, UT, USA) supplemented with 10\% fetal bovine serum (SH30068; Hyclone) and $1 \%$ penicillin-streptomycin (SV30010; Hyclone). Flushed cells were incubated at $37^{\circ} \mathrm{C}$ in a humidified $5 \%$ $\mathrm{CO}_{2}$ atmosphere. After 24 hours, the non-adherent cells were removed by changing the culture medium. Adhered cells were cultured with the medium refreshed every 3 days. When cells reached $80 \%-90 \%$ confluence, they were detached by $0.25 \%$
trypsin/EDTA (SH30042; Hyclone) and seeded at a density of $2 \times 10^{4} / \mathrm{cm}^{2}$. Cells of passage $2-4$ were used in the study.

\section{Cell adhesion and morphology}

To observe the cell morphology, cells were seeded directly on the coated Ti samples and examined by FESEM. After 1 day of culture, the cells were gently washed with PBS three times, fixed with $2.5 \%$ glutaraldehyde overnight at $4^{\circ} \mathrm{C}$, dehydrated through a series of graded ethanol, and gold sputtered in vacuum before FESEM observation.

For the immunofluorescence assay, the BMSCs were fixed with 4\% paraformaldehyde for 15 minutes, washed with PBS, and permeabilized with $0.3 \%$ Triton X-100 for 15 minutes. The cells were then incubated in $1 \%$ bovine serum albumin for 30 minutes to block the nonspecific binding sites. Afterwards, the filamentous actin of the cells was stained by rhodamine phalloidin (R-415 kit; Molecular Probes, Thermo Fisher Scientific) for 20 minutes and the nuclei were stained with 2-(4-amidinophenyl)-6-indolecarbamidine dihydrochloride (Thermo Fisher Scientific) for 15 minutes, successively. The samples were then rinsed again with PBS and stored in glycerol. Immunofluorescence images were obtained using fluorescence microscopy (Nikon TE-2000).

\section{Cell proliferation}

Cell proliferation was analyzed by cell counting kit-8 (CCK-8; Dojindo Laboratories, Kumamoto, Japan). On day 1, 4, and 7, the cell culture plates were washed with PBS, and supplied with $400 \mu \mathrm{L} \alpha$-MEM containing 10\% CCK-8. Then, the culture plates were incubated at $37^{\circ} \mathrm{C}$ for 1 hour and the absorbance value of the supernatant at $450 \mathrm{~nm}$ was read using an ELX808 ultra microplate reader (BioTek Instruments Inc, Winooski, VT, USA).

\section{Cytotoxicity of coatings versus pure $\mathrm{Cu}$ ions}

The cytotoxicity of the deposited coatings was compared with the pure $\mathrm{Cu}$ ions. First, medium extracts were obtained by placing the coated disks in 24 -well tissue plates with cell culture medium for 24 hours. Then, culture medium with the same concentration of $\mathrm{Cu}$ was prepared by adding $\mathrm{Cu}$ chloride solution into the medium. Finally, BMSCs were incubated with both kinds of medium for 24 hours; the medium was then displaced by CCK- 8 solution, and the optical density value at $450 \mathrm{~nm}$ was read.

\section{Real-time quantitative polymerase chain reaction (RT-qPCR) for angiogenesis-related gene expression} At time points of 3, 7, 14 days, RT-qPCR was executed to assess angiogenesis-related gene expressions of various 
samples in BMSCs. Total RNA was extracted using $1 \mathrm{~mL}$ Trizol regent (Takara, Shiga, Japan), the complementary DNA (cDNA) was reverse-transcribed from $1 \mathrm{mg}$ total RNA using a PrimeScript 1st Strand cDNA Synthesis Kit (Takara). Afterwards, the expressions of key angiogenic factors including HIF-1 $\alpha$ and VEGF were measured on Bio-Rad MyiQ single color RT-PCR system using an SYBR green PCR kit (Takara). The relative expressions of target genes were normalized to that of the housekeeping gene glyceraldehyde-3-phosphate dehydrogenase.

Alkaline phosphatase (ALP) activity and RT-qPCR for osteogenesis-related gene expression

For ALP activity assay, BMSCs were cultured with medium supplemented with $10 \mathrm{nM}$ dexamethasone, $10 \mathrm{mM}$ $\beta$-glycerolphosphate, and $50 \mu \mathrm{g} / \mathrm{mL}$ ascorbic acid (Sigma Aldrich). After being cultured for 7 and 14 days, cells were lysed with $0.1 \%$ Triton X-100. The total cellular ALP activity of the samples was measured by reacting with p-nitrophenyl phosphate (P5994; Sigma Aldrich) in alkaline buffer solution (A9226; Sigma Aldrich) at $37^{\circ} \mathrm{C}$ for 1 hour. The absorbance value at $405 \mathrm{~nm}$ was measured with an enzyme linked immunosorbent assay microplate reader using 4-nitrophenol as standard (0-25 nM; N7660; Sigma Aldrich). The intracellular total protein content was determined by the BCA kit (23235; Thermo Fisher Scientific). Finally, the ALP activity was normalized to the total protein content.

To further determine the role of $\mathrm{Cu}-\mathrm{CSG}$ coatings in osteogenic activity in vitro, the expressions of osteogenesisrelated genes including ALP, osteocalcin (OCN), runt-related transcription factor 2 (Runx2), and collagen I (Col-1) in BMSCs were evaluated by RT-qPCR according to the method described before.

\section{Statistical analysis}

One-way analysis of variance and post hoc Tukey testing were carried out using SPSS 16.0 (SPSS Inc, Chicago, IL, USA) for statistical analysis. *,**, and *** stand for $P<0.05$, $P<0.01$, and $P<0.001$, respectively. $P<0.05$ was considered to be statistically significant.

\section{Results}

Physicochemical characterization of the deposited coatings

Surface topography and microstructural characterization

Figure 1A shows that with increasing amount of $\mathrm{Cu}$ in the EPD suspension, the color of the solution changed gradually

\section{A}

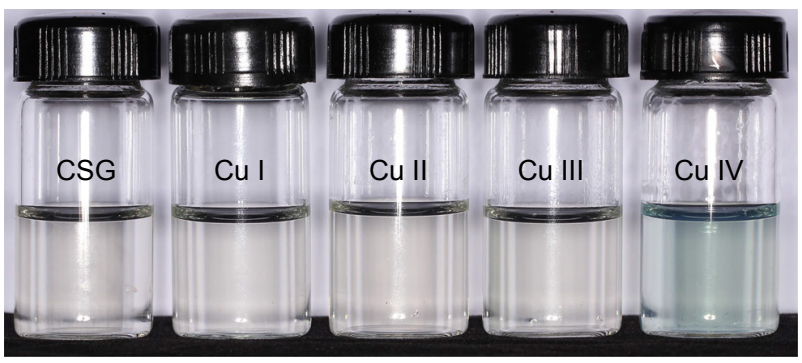

B
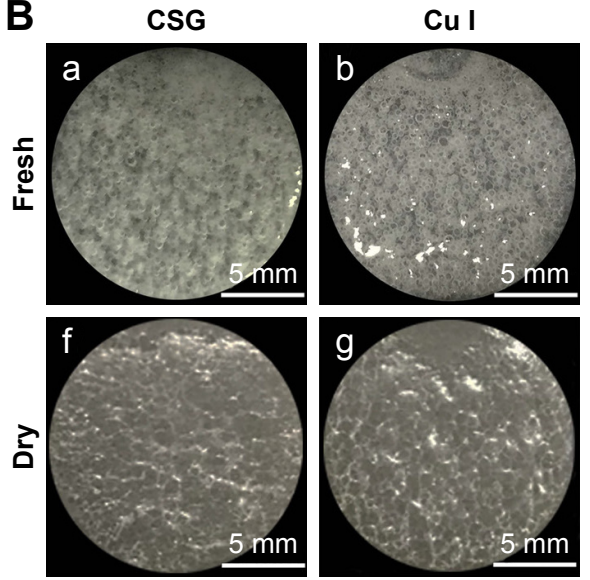

Cu II
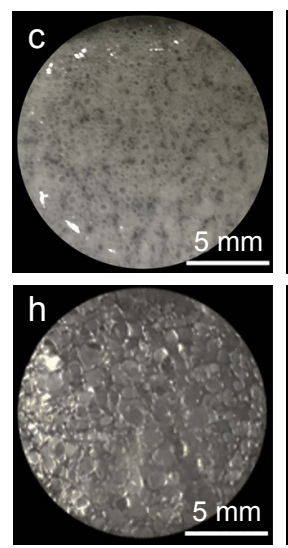

Cu III
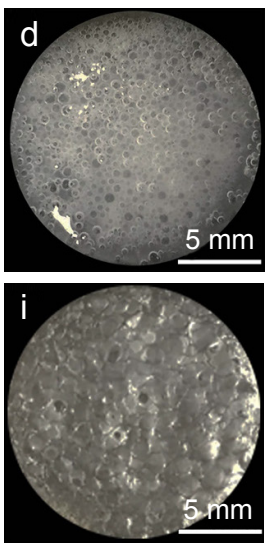

Cu IV
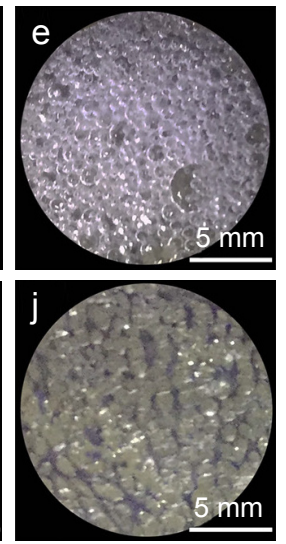

Figure I (A) Optical images of the electrophoretic solution and (B) the coatings.

Note: (B) shows optical images of the $(\mathbf{a}-\mathbf{e})$ fresh and $(\mathbf{f}-\mathbf{j})$ dry coatings.

Abbreviation: CSG, chitosan-gelatin. 
from transparent to light blue. Upon visual inspection, porous hydrogel coatings were uniformly deposited on the substrates after EPD (Figure 1B, upper row), and the sample of the $\mathrm{Cu}$ IV group presented a purplish color. After being air-dried, the coatings showed a thin film-like structure on the Ti disks (Figure 1B, lower row).

As shown in Figure 2A, monodispersed nanoscale particles were observed in the fresh coatings of all five groups. These particles were formed by a cluster of smaller nanoparticles. Fluorescence images of the wet coatings displayed macroporous morphology, with pore sizes ranging from 20 to $300 \mu \mathrm{m}$ (Figure $2 \mathrm{Ba}-\mathrm{Be}$ ). Furthermore, similar to the optical images, the purple fluorescence became obvious with increasing amounts of $\mathrm{Cu}$ in the coatings.

Under low magnification of FESEM (Figure 2Bf-Bo), microscale particles were homogeneously distributed in the $\mathrm{Cu}$-containing groups, while the CSG coating displayed a smooth surface morphology. Nanoscale structures were found in high magnification FESEM images (Figure $2 \mathrm{Bp}-\mathrm{Bt}$ ). In the $\mathrm{Cu} \mathrm{I}-\mathrm{III}$ groups, the nanoscale

A
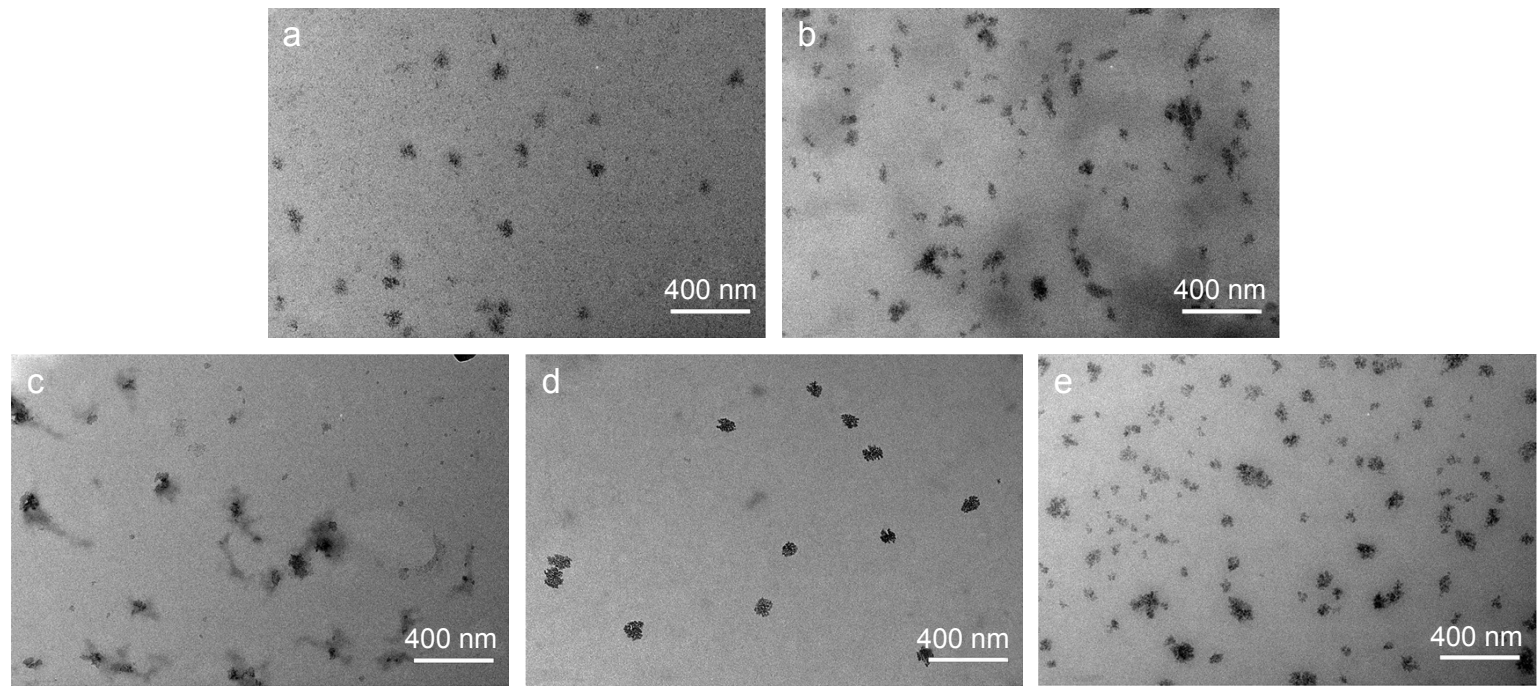

B

CSG

Cu I
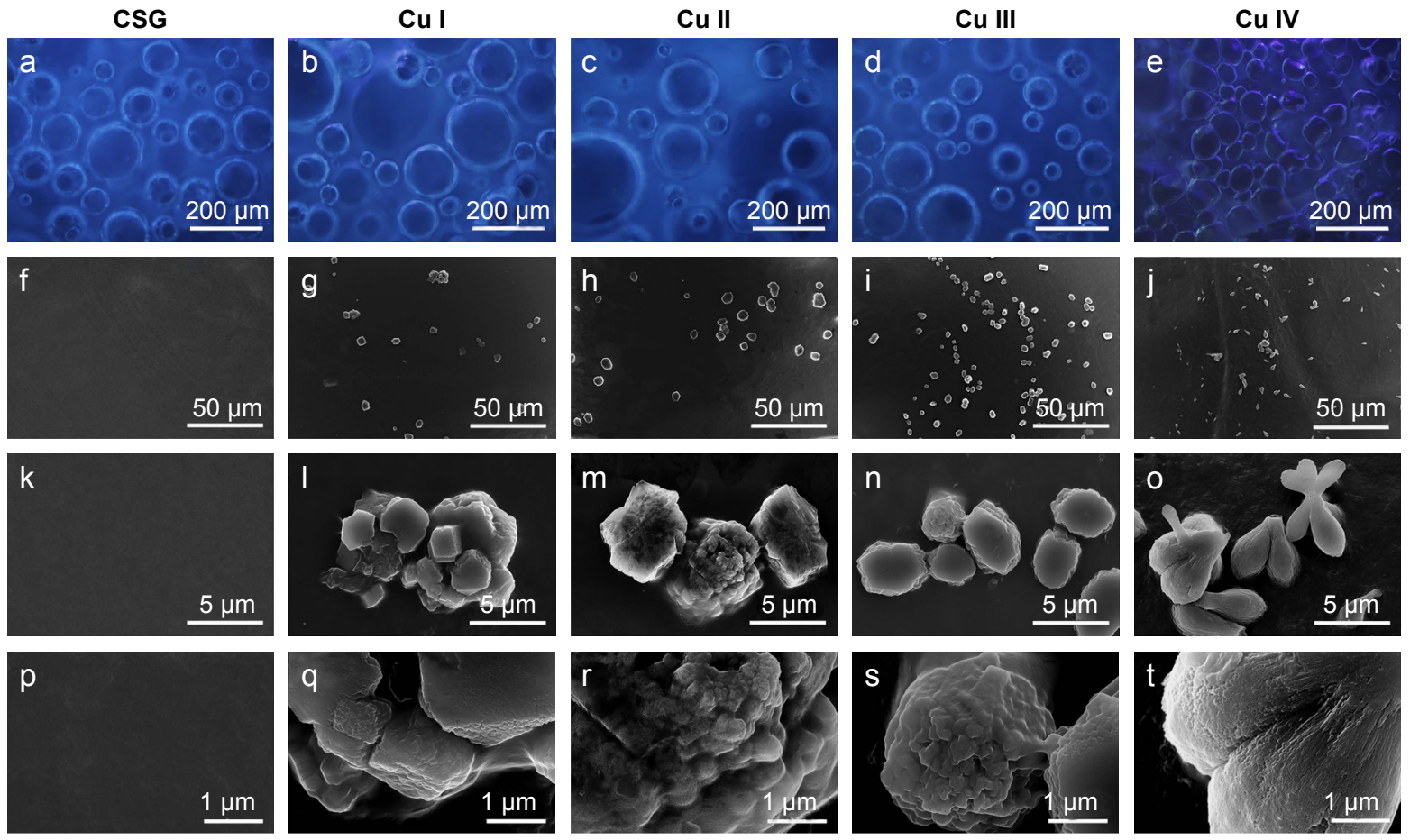

Figure 2 Micro-topography of the coatings. (A) TEM images of the freshly made coatings: (a) CSG; (b) Cu I; (c) Cu II; (d) Cu III; (e) Cu IV. (B) (a-e) Fluorescence images, (f-o) low magnification FESEM, ( $\mathbf{p}-\mathbf{t})$ high magnification FESEM.

Abbreviations: CSG, chitosan-gelatin; TEM, transmission electron microscopy; FESEM, field emission scanning electron microscopy. 
structures exhibited a nanosphere-like structure, while the $\mathrm{Cu}$ IV group showed a condensed bundle-like morphology with nano-size diameter.

EDS analysis confirmed the presence of $\mathrm{Cu}$ in $\mathrm{Cu}$ II-IV coatings while the spectra of $\mathrm{Cu}$ I group showed no peak of $\mathrm{Cu}$, probably due to the extreme low concentration (Figure 3A). The relative amount of $\mathrm{Cu}$ in the coatings increased from $\mathrm{Cu}$ II to IV. CSG coating did not show any $\mathrm{Cu}$ peak.

The FTIR spectra (Figure 3B) of all coatings exhibited strong absorption peaks at about 1,151, 1,068, and $1,030 \mathrm{~cm}^{-1}$, which were characteristic of $\mathrm{C}-\mathrm{N}$ stretching, $\mathrm{C}-\mathrm{O}$ stretching, and $\mathrm{O}-\mathrm{H}$ bending in chitosan. ${ }^{34}$ In addition, the characteristic peaks of gelatin at $1,635,1,556 \mathrm{~cm}^{-1}$ due to amide I, - CONH- stretching and amide II, -NH2 stretching were also observed..$^{35}$ In the four $\mathrm{Cu}$-containing groups, slight changes occurred in the position and intensity of the peaks compared with the CSG group.

The XPS full spectra obtained from the surfaces of samples are shown in Figure 3C. On the basis of these results, the $\mathrm{Cu}$ element was detected in the $\mathrm{Cu}$ III and $\mathrm{Cu}$ IV group with contents of $0.25 \%$ and $2.74 \%$, respectively. As presented in Figure 3D, the $\mathrm{Cu} 2 \mathrm{p}$ doublet of the $\mathrm{Cu} \mathrm{IV}$ group located at $952.25 \mathrm{eV}$ and $932.74 \mathrm{eV}$ corresponded with the binding energies of $\mathrm{Cu} 2 \mathrm{p}_{1 / 2}$ and $\mathrm{Cu} 2 \mathrm{p}_{3 / 2}$, respectively, in metallic $\mathrm{Cu}{ }^{16}$

\section{Cu entrapment and release assay}

Figure 4A shows that the amount of $\mathrm{Cu}$ entrapped in each sample was $0.177 \pm 0.024 \mu \mathrm{g}$ for the $\mathrm{Cu}$ I group, $1.308 \pm 0.346 \mu \mathrm{g}$ for the $\mathrm{Cu}$ II group, $11.92 \pm 2.154 \mu \mathrm{g}$ for the $\mathrm{Cu}$ III group, and $68.29 \pm 2.306 \mu \mathrm{g}$ for the $\mathrm{Cu} \mathrm{IV}$ group.
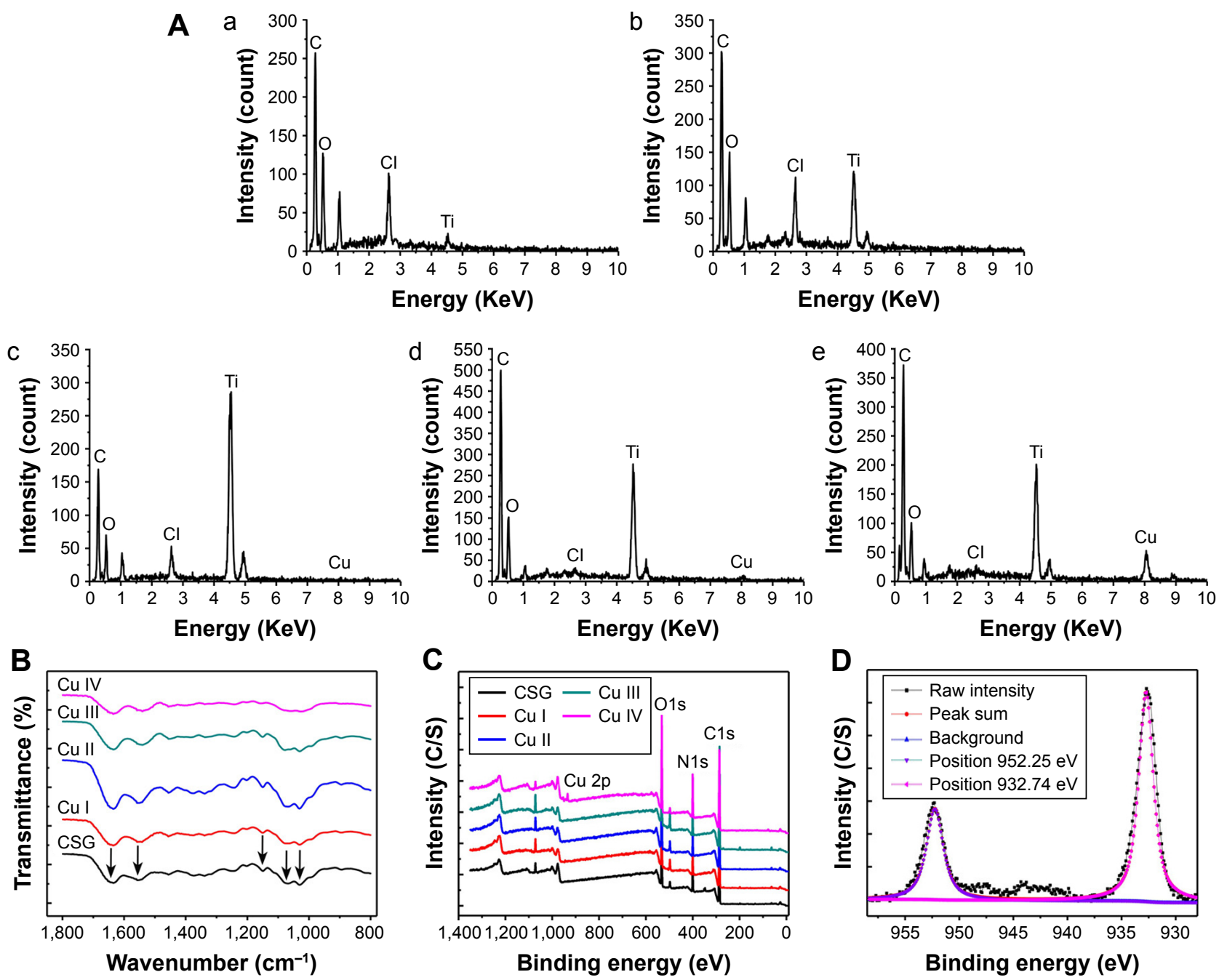

Figure 3 (A) EDS of the coatings: (a) CSG; (b) Cu I; (c) Cu II; (d) Cu III; (e) Cu IV. (B) ATR-FTIR spectra of CSG and Cu-containing coatings. (C) Surface XPS full spectra of coatings with/without $\mathrm{Cu}$ doping. (D) High-resolution XPS spectra of $\mathrm{Cu} 2 \mathrm{p}$ of the $\mathrm{Cu}$ IV coatings.

Abbreviations: CSG, chitosan-gelatin; EDS, energy-dispersive X-ray spectrometry; ATR-FTIR, attenuated total reflection Fourier transform infrared spectroscopy; XPS, X-ray photoelectron spectroscopy. 

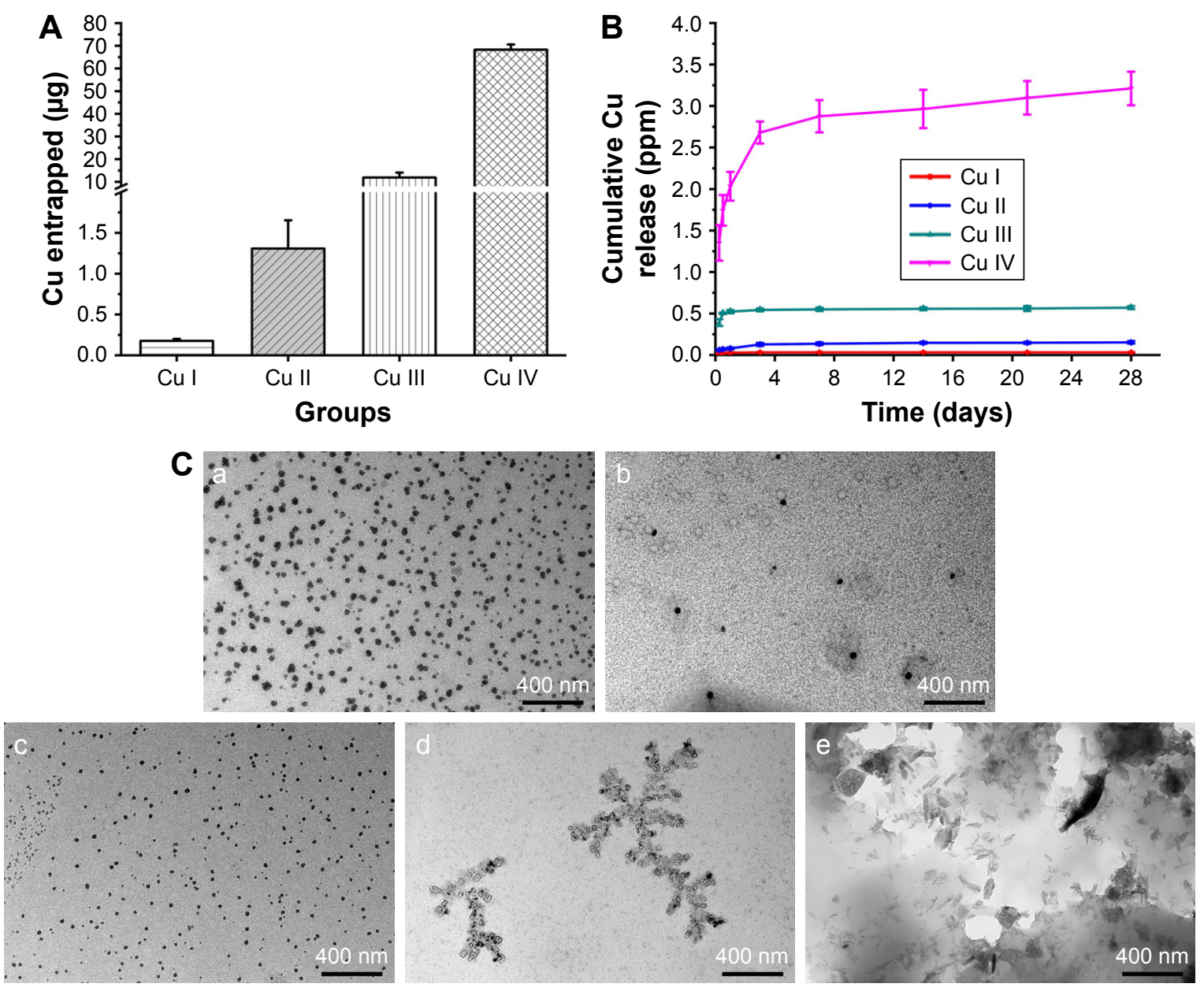

Figure 4 (A) Cu entrapment of the copper-containing coatings. (B) Cumulative release profiles of copper released from copper-doped coatings in PBS. (C) TEM images of the released nanoparticles: (a) CSG; (b) Cu I; (c) Cu II; (d) Cu III; (e) Cu IV.

Abbreviations: CSG, chitosan-gelatin; PBS, phosphate-buffered saline; TEM, transmission electron microscopy.

The percentages of entrapped $\mathrm{Cu}$ to the entire coating were about $0.00268 \%, 0.02 \%, 0.25 \%$, and $2.2 \%$ by weight, respectively, for $\mathrm{Cu}$ I-IV groups (data not shown).

In the $\mathrm{Cu}$ release assay (Figure 4B), the $\mathrm{Cu} \mathrm{I}, \mathrm{Cu} \mathrm{II}$, and $\mathrm{Cu}$ III coatings showed an initial burst release on the first day of observation, and very little amount of $\mathrm{Cu}$ was released in the following days. However, in the Cu IV group, sustained release could be observed throughout the whole experiment. Significant differences in the amount of released $\mathrm{Cu}$ could be found between $\mathrm{Cu}$ I group and $\mathrm{Cu}$ II or $\mathrm{Cu}$ III group. The percentages of released $\mathrm{Cu}$ during the 28 days were about $90 \%, 58.4 \%, 23.9 \%$, and $23 \%$, respectively, for $\mathrm{Cu}$ I-IV groups.

TEM images (Figure 4C) display the morphology of the nanocomposites released from the coatings. For the CSG, $\mathrm{Cu} \mathrm{I}$, and $\mathrm{Cu}$ II groups, nanosphere structure could be observed. In the $\mathrm{Cu}$ III group, square and oval shaped nanoscale particles appeared, which were arranged in dendritic structure. For the $\mathrm{Cu}$ IV group, the released particles presented a rod-like morphology with diameters of 2-20 nm and lengths of 20-200 nm.

\section{Swelling ratio}

As presented in Figure 5A, the swelling ratio of all groups shot up to about $1,300 \%$ in 30 minutes. After that, the ratio decreased gradually and remained stable at around $850 \%$. This is also supported by the thickness measurement, which showed that the dried coatings and the PBS-soaked coatings were about 35 and $390 \mu \mathrm{m}$, respectively.

\section{Degradation rate}

The degradation rate of the coatings is shown in Figure 5B. The weight of all the samples decreased sharply in the first 7 days, followed by relatively little change in the following days. It is noteworthy that the weight loss rate decreased as the amount of $\mathrm{Cu}$ in the coating increased. At the end of the 

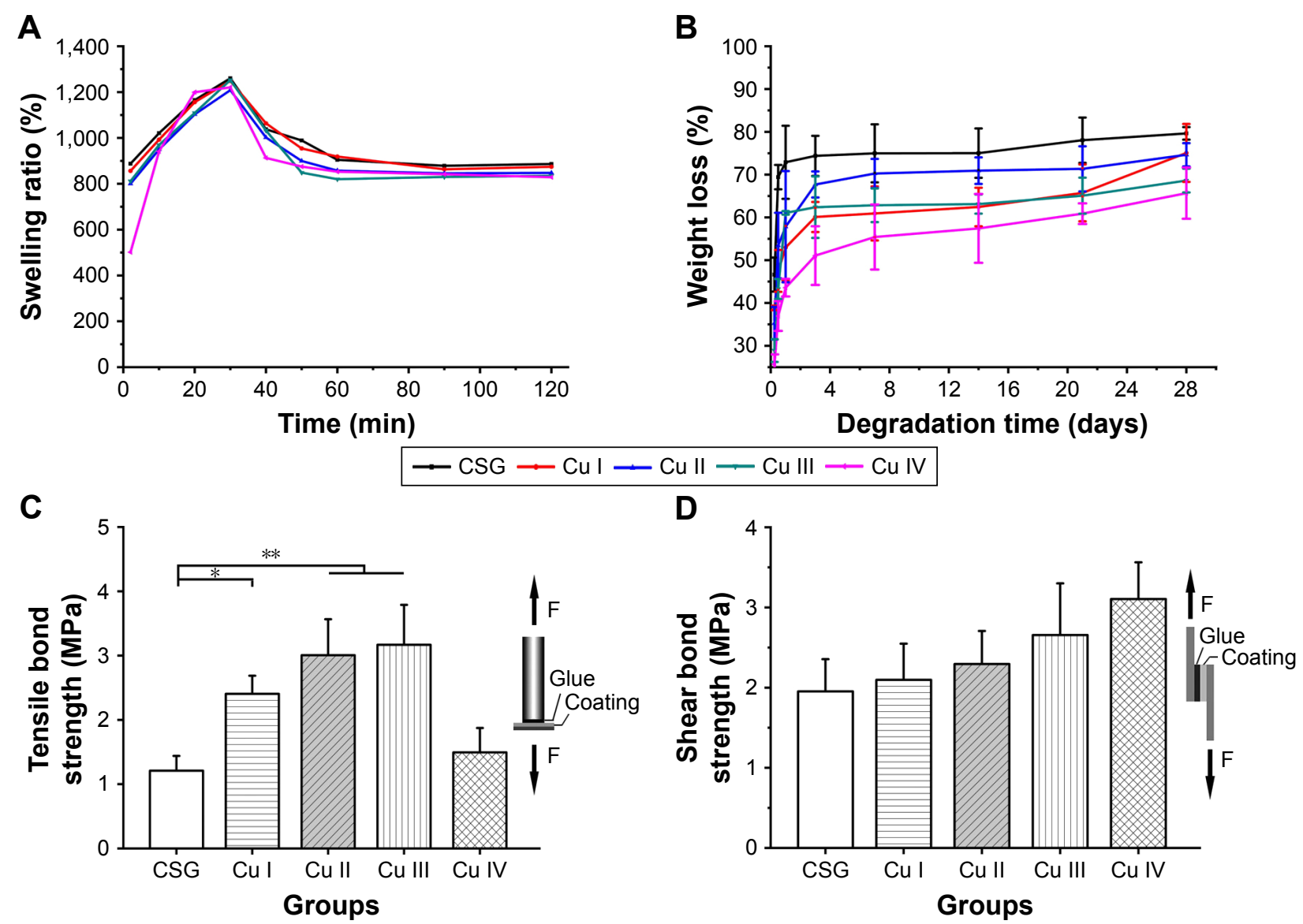

Figure 5 (A) Swelling ratio and (B) degradation rate of all the coatings. (C) Tensile bond strengths and (D) shear bond strengths of different coatings on titanium substrates. $\mathrm{n}=3 ; * \mathrm{P}<0.05, * * \mathrm{p}<0.01$.

Abbreviation: CSG, chitosan-gelatin.

study, the weight loss of the CSG and Cu I-IV groups was $79.6 \%, 75.0 \%, 74.6 \%, 68.6 \%$, and $65.7 \%$, respectively.

\section{Mechanical property}

During the mechanical tests, all the coatings were detached from the substrate, and failures occurred at the coating-Ti interface rather than the coating-gel interface. As shown in Figure $5 \mathrm{C}$, the tensile bond strength of the coatings increased when $\mathrm{Cu}$ was introduced in $\mathrm{Cu}$ I-III groups. However, in the $\mathrm{Cu}$ IV group, the tensile bond strength had no difference compared with the CSG group. As for the shear bond strength (Figure 5D), there was no significant difference among all the groups.

\section{In vitro antibacterial study \\ Observation of the bacteria by FESEM}

Bacteria adhered on the surface of the coatings were observed by FESEM. It was shown that the amounts of $E$. coli and $S$. aureus on the surfaces decreased with increasing $\mathrm{Cu}$ concentration in the coatings (Figures $6 \mathrm{~A}-\mathrm{E}$ and $7 \mathrm{~A}-\mathrm{E}$ ).
Furthermore, E. coli of CSG, Cu I, Cu II, and Cu III groups showed typical intact and rod-like morphology, while in the $\mathrm{Cu}$ IV group, the bacteria were shriveled to spherical shape, even with the membrane perforated (Figure 6E, white arrow). As for S. aureus, the bacteria that spread on the CSG, $\mathrm{Cu}$ I, and $\mathrm{Cu}$ II groups exhibited typical spherical morphology, while shriveled and deformed membranes (Figure 7D and $\mathrm{E}$, white arrow) were detected in $\mathrm{Cu}$ III and $\mathrm{Cu}$ IV groups.

\section{Live/Dead staining}

Figures $6 \mathrm{~F}-\mathrm{T}$ and $7 \mathrm{~F}-\mathrm{T}$ show the fluorescent images of bacteria of various groups after Live/Dead staining. For both E. coli and $\mathrm{S}$. aureus, as $\mathrm{Cu}$ concentration increased from $\mathrm{CSG}$ to $\mathrm{Cu} \mathrm{IV}$, the green fluorescent intensity (live bacterial colonies) decreased, while the red fluorescent intensity (dead bacterial colonies) increased. A quantitative analysis of Live/Dead staining is displayed in Figure 8A and B. The counts of live bacteria decreased markedly (from 1,444 to 67 for E. coli, from 645 to 60 for $S$. aureus) and the counts of dead bacteria drastically increased (from 60 to 1,143 for 

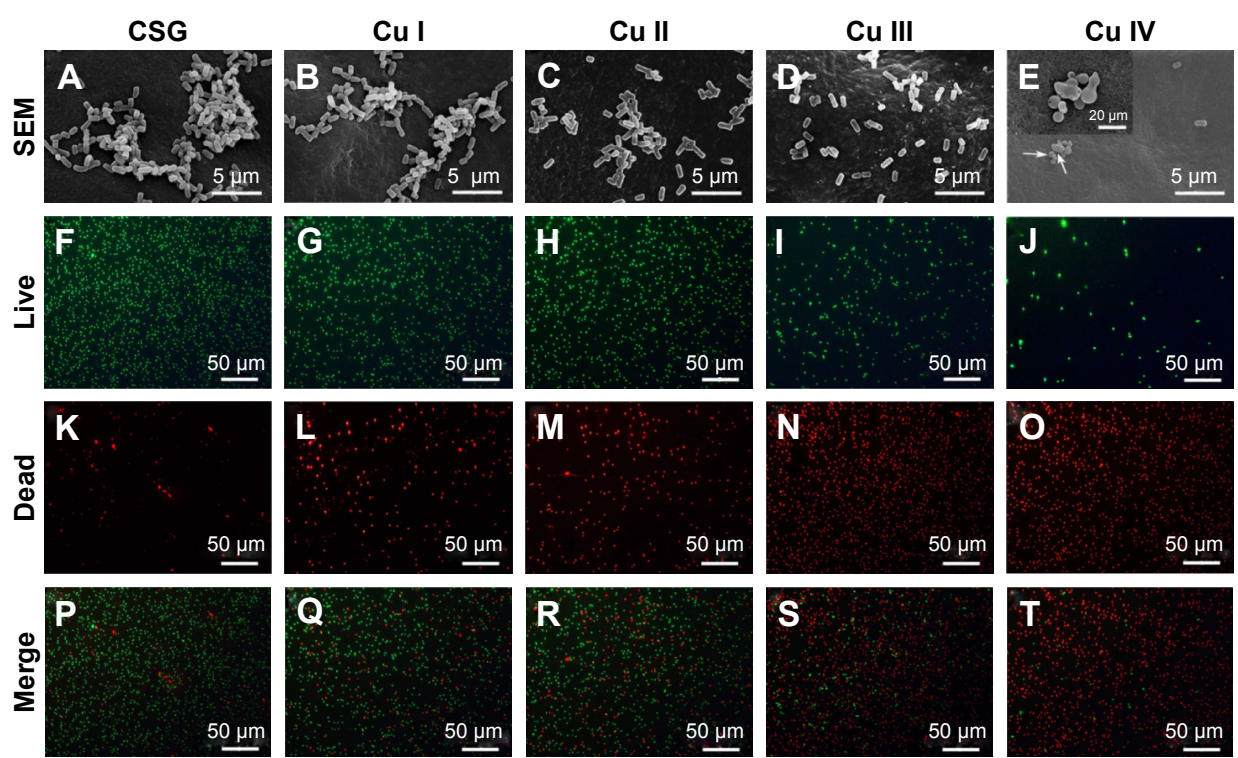

Figure 6 (A-E) FESEM morphologies of E. coli adhered on the deposited coatings. The arrows in (E) indicate that the bacteria of group Cu IV were shriveled to spherical shape, even with the membrane perforated. (F-T) Live/Dead stain fluorescent images of $E$. coli after dyeing with SYTO 9 and PI.

Abbreviations: CSG, chitosan-gelatin; FESEM, field emission scanning electron microscopy; PI, propidium iodide.

E. coli, from 59 to 787 for $S$. aureus) as the concentration of $\mathrm{Cu}$ increased.

\section{Quantitative measurements of antibacterial property}

To quantify the antibacterial ability of $\mathrm{Cu}$-containing samples against both species, the bacteria that adhered on the surfaces and were suspended in the culture medium were recultivated on agar plates according to the bacteria counting method (Figure 8C). As shown in Figure 8D, for E. coli, the $\mathrm{Ra}$ values of $\mathrm{Cu}$ I, $\mathrm{Cu}$ II, $\mathrm{Cu}$ III, and $\mathrm{Cu}$ IV groups were $12.9 \%, 31.2 \%, 83.9 \%$, and $97.8 \%$, respectively, and $\mathrm{Rp}$ values were $21.1 \%, 37.3 \%, 85.2 \%$, and $98 \%$, respectively. As for S. aureus, Ra was $65.9 \%, 68.6 \%, 84.7 \%$, and $91.7 \%$, respectively, and $\mathrm{Rp}$ values were $69.4 \%, 69.2 \%, 83.2 \%$, and $94.8 \%$, respectively.

\section{Leakage of protein from bacteria}

Results suggested that only the $\mathrm{Cu}$ IV group could enhance membrane leakage of proteins in E. coli compared with the CSG group. As for S. aureus, the leakage of proteins in the $\mathrm{Cu}$ III and $\mathrm{Cu}$ IV coatings was significantly higher than that in the CSG group (Figure 9).

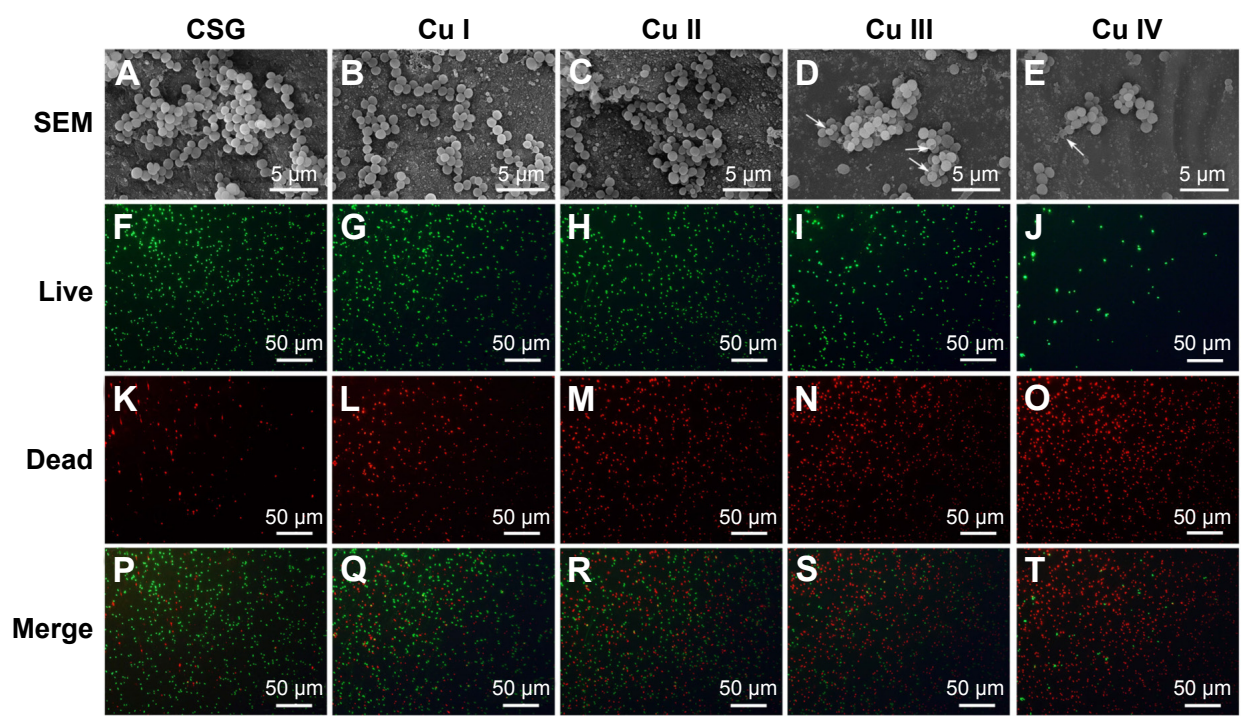

Figure 7 (A-E) FESEM morphologies of S. aureus adhered on the deposited coatings. The arrows in $\mathbf{D}$ and $\mathbf{E}$ indicated that shriveled and deformed membranes were presented by bacteria on Cu III and Cu IV groups. (F-T) Live/Dead stain fluorescent images of S. aureus after dyeing with SYTO 9 and PI.

Abbreviations: CSG, chitosan-gelatin; FESEM, field emission scanning electron microscopy; PI, propidium iodide. 
A

$$
\text { A }
$$

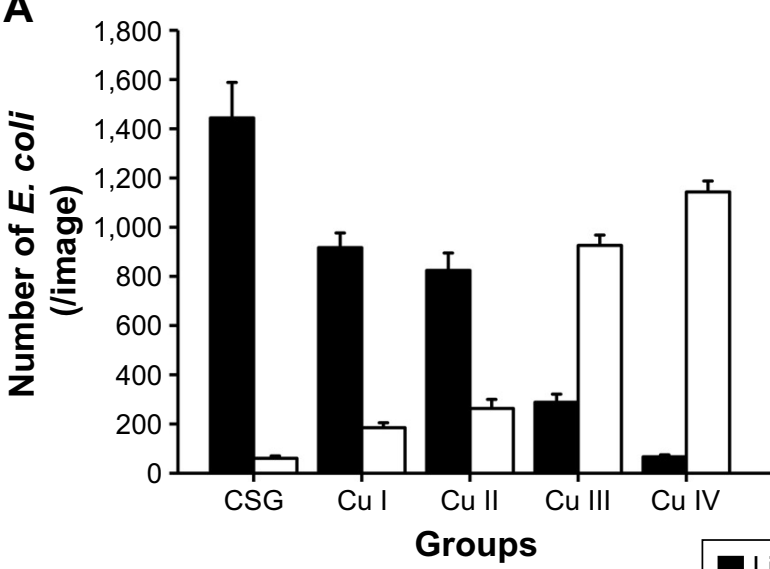

B

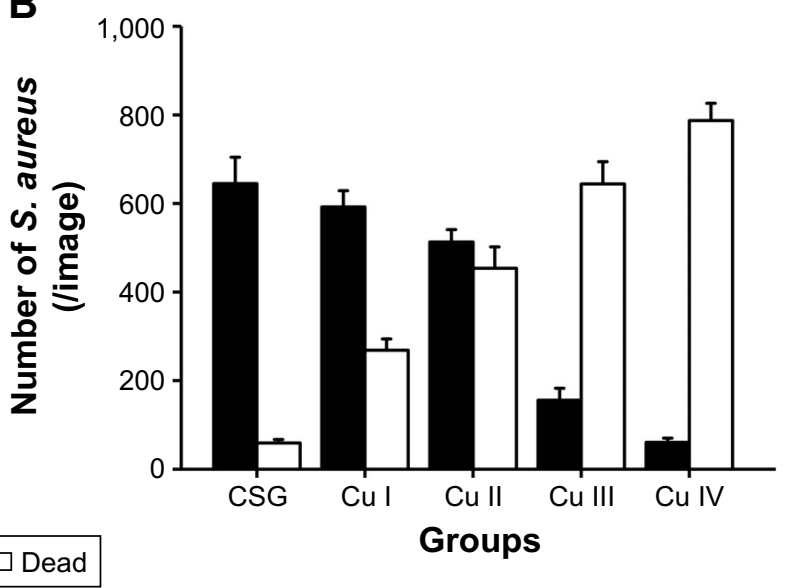

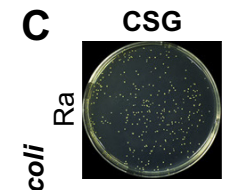
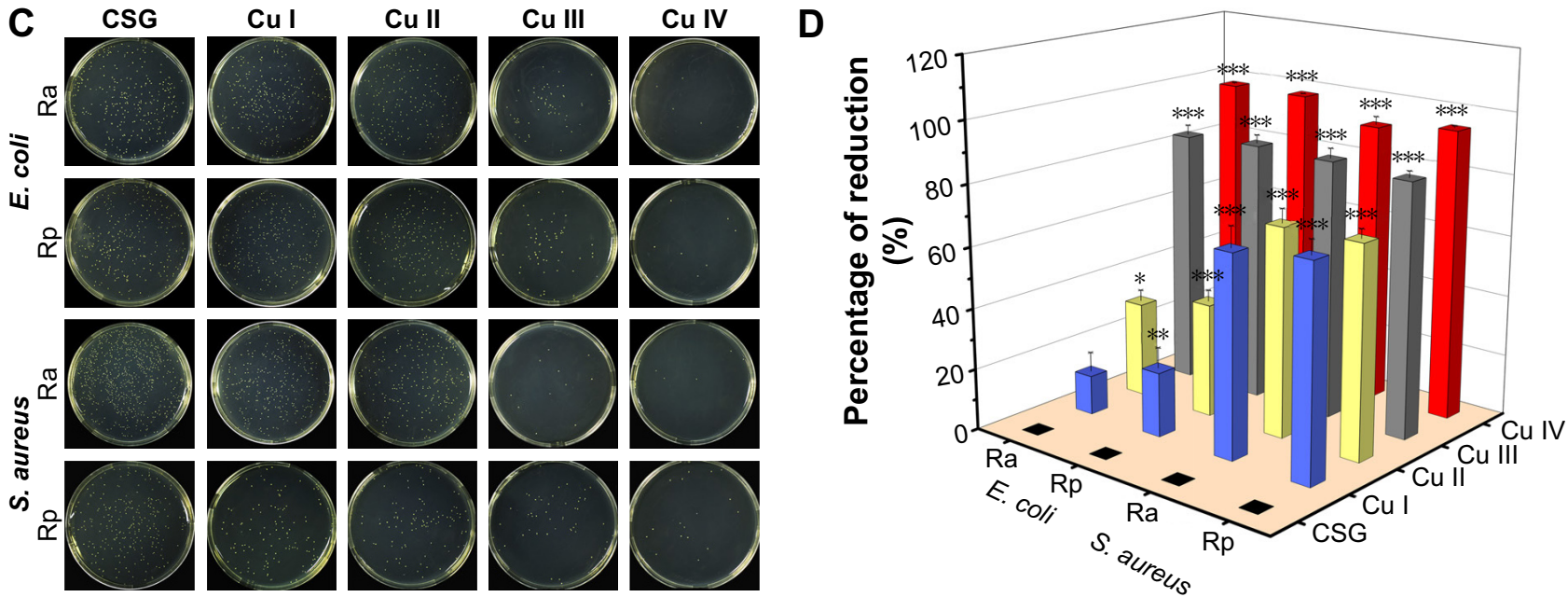

Figure 8 Number of Live/Dead E. coli per image (A) and S. aureus per image (B) after dyeing with SYTO 9 and PI. (C) Typical photographs of recultivated bacterial colonies on agar and (D) corresponding antibacterial ratios of $\mathrm{Ra}$ and $\mathrm{Rp} . \mathrm{n}=3 ; * \mathrm{P}<0.05, * * P<0.01$, and $* * * P<0.00$ I versus the CSG group.

Abbreviations: CSG, chitosan-gelatin; PI, propidium iodide; Ra, antibacterial rate for adherent bacteria; Rp, antibacterial rate for planktonic bacteria.

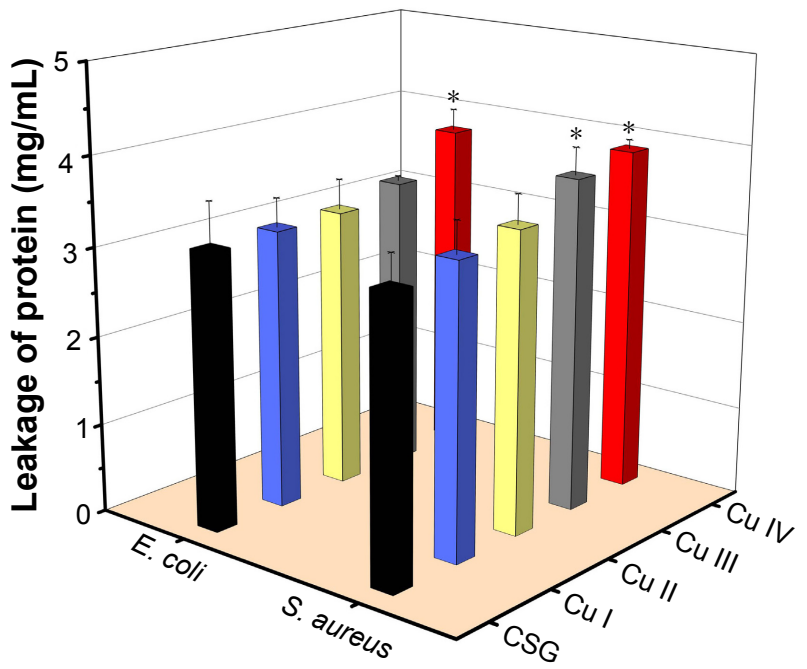

Figure 9 Effects of Cu-containing samples on the membrane leakage of proteins from $E$. coli and S. aureus after 6 hours of incubation. $n=3 ; * p<0.05$ versus the CSG group.

Abbreviation: CSG, chitosan-gelatin.

\section{In vitro cellular study}

\section{Cell adhesion and morphology}

In order to observe cell adhesion and morphology, BMSCs cultured on different samples for 24 hours were examined by FESEM and fluorescence microscopy (Figure 10A). FESEM results indicated that $\mathrm{Cu}$-incorporated coatings could support BMSCs attachment and spreading. In addition, cytoskeleton staining of all groups exhibited a polygonal shape with extended filopodia and lamellipodia (marked with white arrow). No apparent differences were found except that the cell density of the $\mathrm{Cu}$ IV group was less than all other groups.

\section{Cell proliferation}

The CCK-8 assay results in Figure 10B show the viability and proliferation of BMSCs in various samples. In general, cell population in all samples increased from day 1 to 7 with 
A

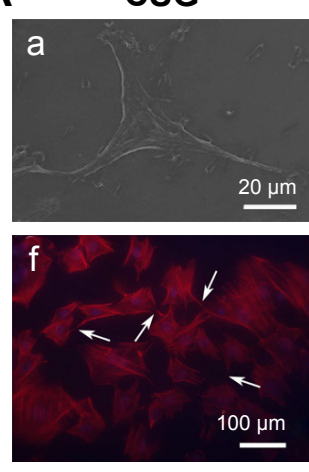

B

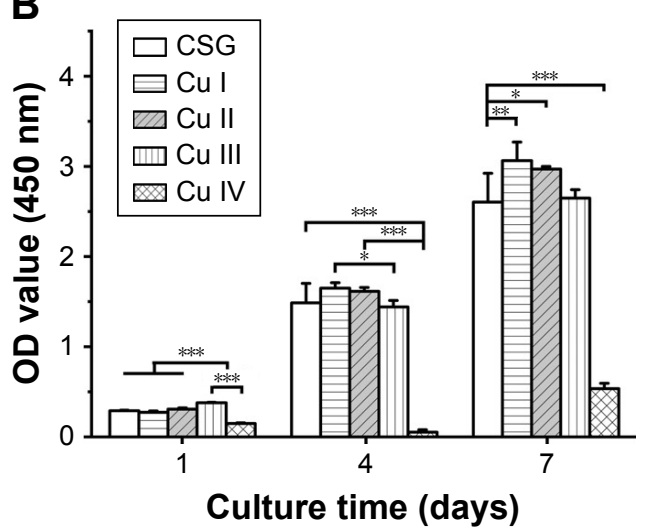

Cu II
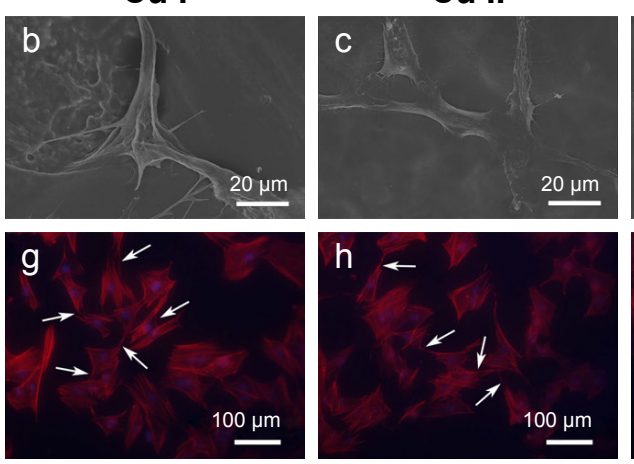

Cu III
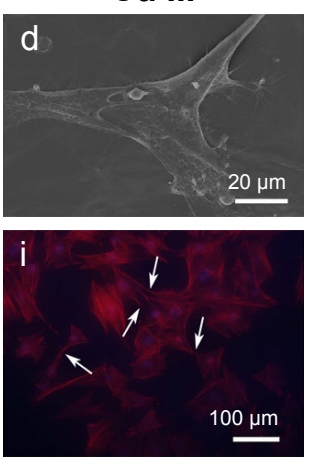

Cu IV
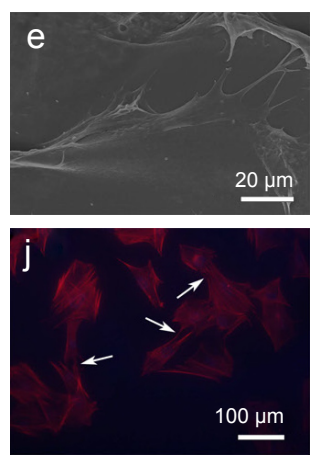

C

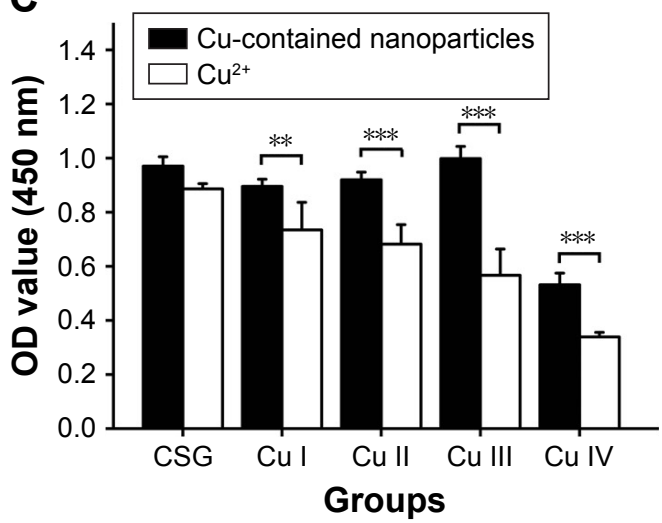

Figure 10 (A) (a-e) FESEM images and ( $\mathbf{f - j}$ ) fluorescence images of BMSCs after I day of culture. The arrows indicate the extended filopodia and lamellipodia of the BMSCs. (B) Cell viability of BMSCs cultured at specific time intervals. (C) Cell viability of BMSCs cultured with medium extracts and medium with the same concentration of copper ions. $\mathrm{n}=6$; $* \mathrm{P}<0.05, * * \mathrm{P}<0.01$, and $* * * \mathrm{P}<0.001$.

Abbreviations: CSG, chitosan-gelatin; FESEM, field emission scanning electron microscopy; BMSCs, bone marrow stromal cells; OD, optical density.

the exception that cell number of the $\mathrm{Cu}$ IV group dropped on day 4. Among all $\mathrm{Cu}$ deposited coatings, $\mathrm{Cu}$ I, II, and III groups manifested similar growth trends as CSG group. On day 7, $\mathrm{Cu}$ I and II even showed higher activity than the CSG group. However, cell activity of the $\mathrm{Cu}$ IV group was significantly lower than that of the CSG group at all time points and was only $25 \%$ of CSG on day 7 . This suggests that high $\mathrm{Cu}$ concentration can inhibit BMSCs activity.

\section{Cytotoxicity of the coatings compared with pure $\mathrm{Cu}$ ions}

CCK-8 tests were conducted to compare the cytotoxicity of the $\mathrm{Cu}$ organic compounds and pure $\mathrm{Cu}$ ions. As shown in Figure 10C, cell activity of the $\mathrm{Cu}$ compounds group was significantly higher than $\mathrm{Cu}$ ion group with the same concentration in all $\mathrm{Cu}$-doped groups. These results indicated that cytotoxicity of the $\mathrm{Cu}$ ions was reduced when assembling with the organic compounds via EPD.

\section{RT-qPCR for angiogenesis-related gene expression}

Key angiogenic factors (HIF- $1 \alpha$ and VEGF) in BMSCs were evaluated using RT-qPCR assay after culturing with various samples for 3, 7, and 14 days (Figure 11). The results are expressed as relative levels over the CSG group. HIF-1 $\alpha$ and VEGF gene expressions followed similar patterns ( $\mathrm{Cu}$ III $>\mathrm{Cu}$ II $>\mathrm{Cu}$ I $\approx \mathrm{CSG}>\mathrm{Cu}$ IV). In particular, $\mathrm{Cu}$ II and $\mathrm{Cu}$ III groups demonstrated significantly upregulated genes expressions of angiogenic factors compared with the CSG group, while the $\mathrm{Cu}$ IV group showed remarkably lower expressions of these genes.

\section{ALP activity and RT-qPCR for osteogenesis-related gene expression}

The quantitative analysis shown in Figure 12A revealed that ALP activity of BMSCs in $\mathrm{Cu}$ I, $\mathrm{Cu}$ II, and $\mathrm{Cu}$ III groups increased as $\mathrm{Cu}$ loading ascended, and it was significantly higher in the $\mathrm{Cu}$ III group than CSG group.

RT-qPCR analysis (Figure 12B-E) show outstanding performance of $\mathrm{Cu}$ III coatings. BMSCs expressions of osteogenesis-related genes, including ALP (early marker for osteogenic differentiation), OCN (late marker for osteogenic differentiation), Runx2 (critical transcription factor for bone formation), and Col-1 (main content of bone extracellular matrix) were dramatically upregulated in $\mathrm{Cu}$ III samples compared with other groups, especially on day 14. All other groups were in a similar range of expression except that 

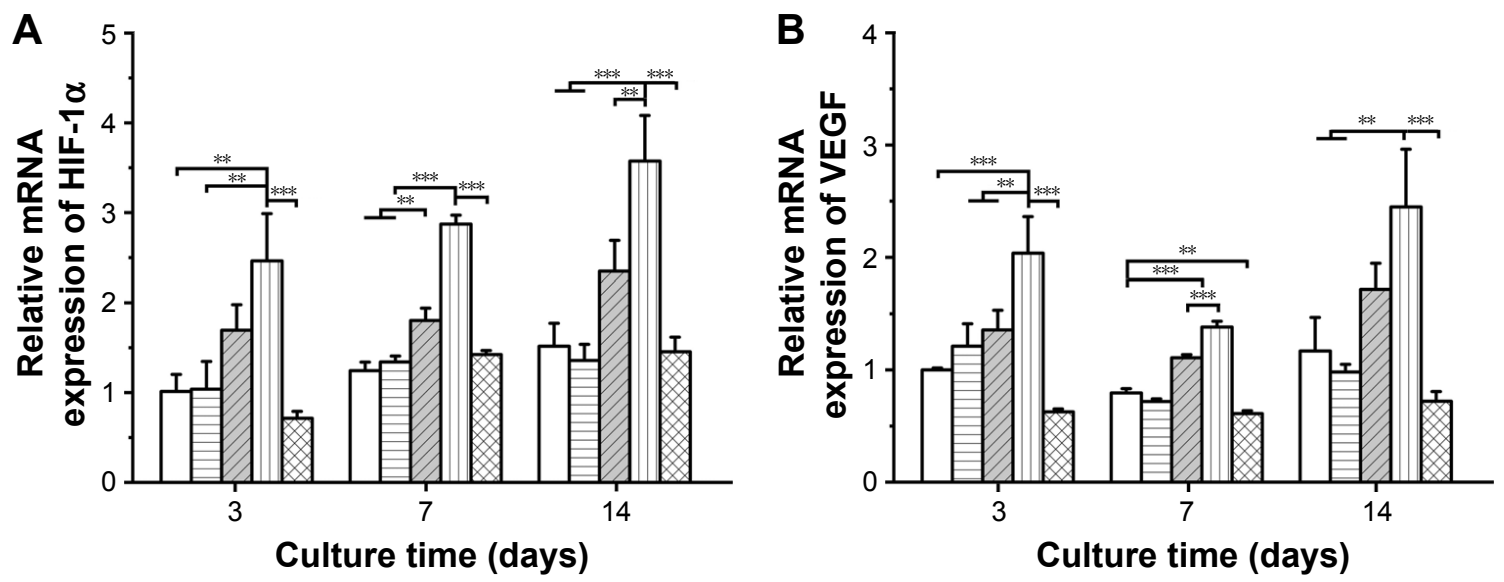

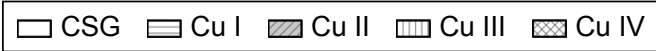

Figure I I Gene expression levels of angiogenesis-related markers: (A) HIF-I $\alpha$ and (B) VEGF in BMSCs cultured with various samples at specific time intervals. $\mathrm{n}=3$; $* * P<0.01$, *** $P<0.001$.

Abbreviations: CSG, chitosan-gelatin; HIF-I $\alpha$, hypoxia inducible factor-I $\alpha$; VEGF, vascular endothelial growth factor; BMSCs, bone marrow stromal cells.

Col-1 expression was apparently lower in the $\mathrm{Cu}$ IV group than in the CSG group.

\section{Discussion}

In the present study, we have successfully fabricated Cu-doped CSG nanocomposite coatings on Ti substrates by an ecofriendly EPD method (the mechanism is illustrated in
Scheme 1). As described in our previous study, chitosan is a linear polysaccharide with a $\mathrm{pKa}$ value near $6.3,{ }^{36}$ and it can be dissolved in $\mathrm{HCl}$ solution $(\mathrm{pH}=4)$ due to protonation of amino groups. Once gelatin is dissolved in chitosan solution, colloidal polyelectrolyte complexes are formed by the electrostatic interaction between $-\mathrm{NH}_{3}^{+}$groups on chitosan and $-\mathrm{COO}^{-}$groups on gelatin. When $\mathrm{Cu}$ chloride solution

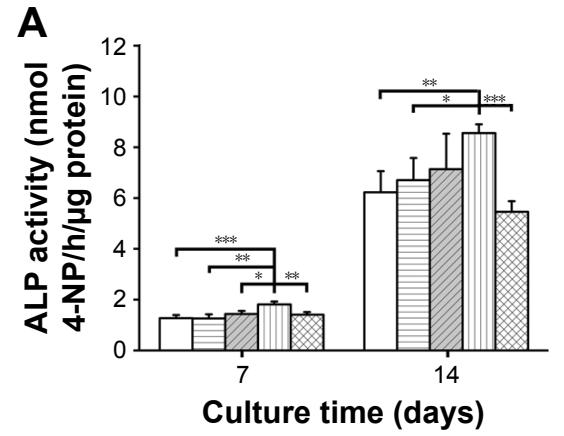

D

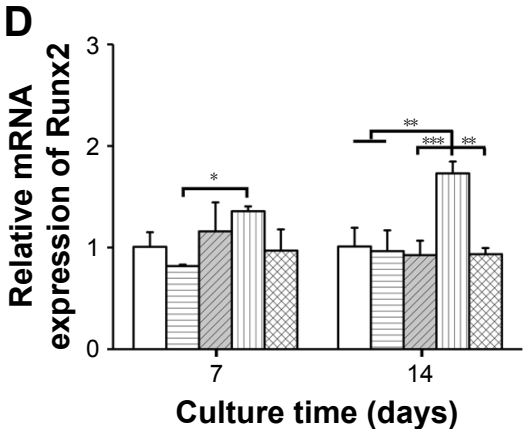

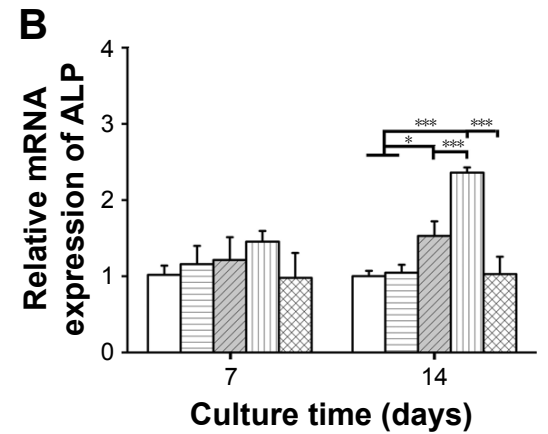

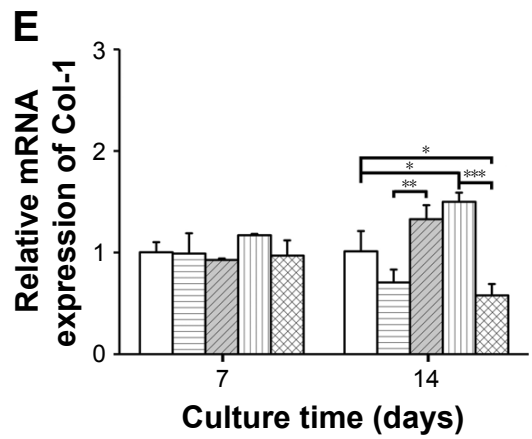

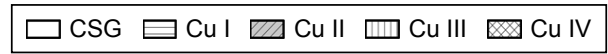

Figure 12 (A) ALP activity and gene expression levels of osteogenesis-related markers: (B) ALP, (C) OCN, (D) Runx2, (E) Col-I in BMSCs cultured with various samples at specific time intervals. $n=3 ; * P<0.05, * * P<0.01$, and $* * * P<0.001$.

Abbreviations: CSG, chitosan-gelatin; ALP, alkaline phosphatase; OCN, osteocalcin; Runx2, runt-related transcription factor 2; Col-I, collagen I; BMSCs, bone marrow stromal cells. 


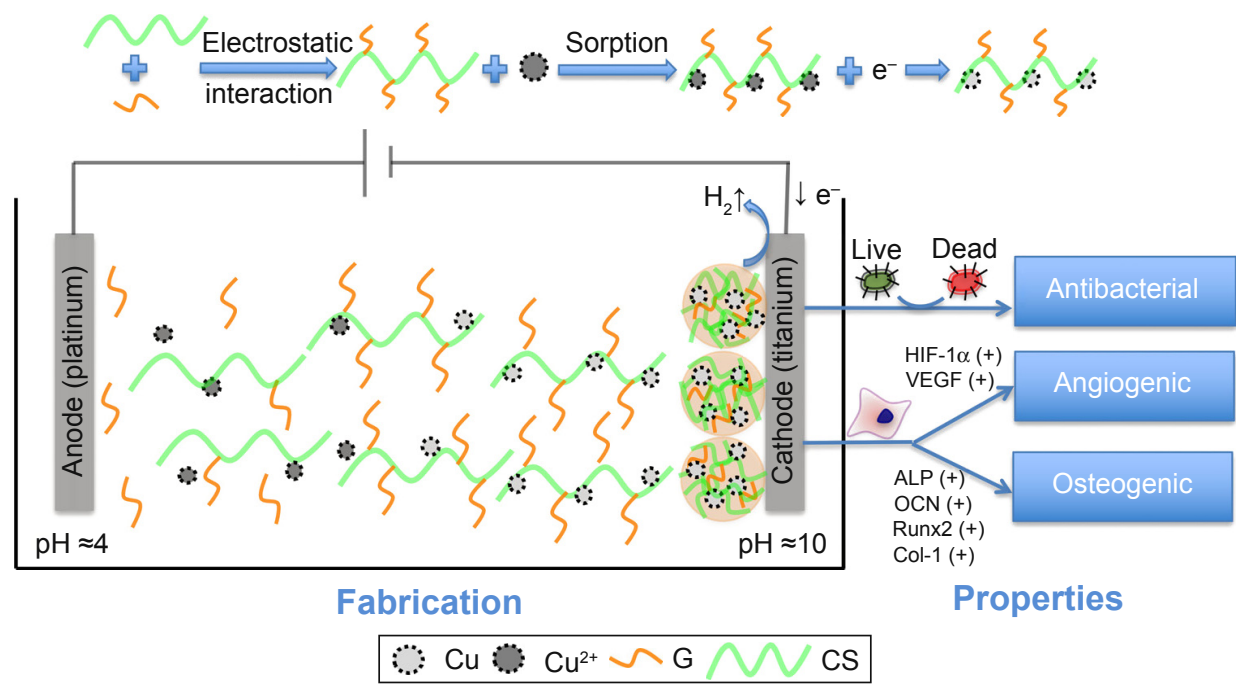

Scheme I Fabrication and properties of Cu-CSG nanocomposite coatings via EPD.

Abbreviations: G, gelatin; CS, chitosan; CSG, chitosan-gelatin; EPD, electrophoretic deposition; HIF-I $\alpha$, hypoxia inducible factor-I $\alpha$; VEGF, vascular endothelial growth factor; ALP, alkaline phosphatase; OCN, osteocalcin; Runx2, runt-related transcription factor 2; Col-I, collagen I.

was added into the CSG suspension, a stable colloid system of $\mathrm{Cu}-\mathrm{CSG}$ complexes was formed through chelation or electrostatic attraction between $\mathrm{Cu}$ and chitosan. ${ }^{37}$ During the EPD process, the $\mathrm{pH}$ value around the cathode rose up to 10 due to the electrolysis of water, ${ }^{38}$ which produced bubbles of hydrogen gas.

$$
\begin{aligned}
& \text { CS-NH }{ }_{2}+\mathrm{H}_{3} \mathrm{O}^{+} \rightarrow \mathrm{CS}^{-\mathrm{NH}_{3}+}+\mathrm{H}_{2} \mathrm{O} \\
& 2 \mathrm{H}_{2} \mathrm{O}+2 \mathrm{e}^{-} \rightarrow \mathrm{H}_{2} \uparrow+2 \mathrm{OH}^{-} \text {(cathode) }
\end{aligned}
$$

Consequently, chitosan confronted a high $\mathrm{pH}$ than its $\mathrm{p}$ Ka near the cathode, where chitosan's amine groups were deprotonated and became insoluble. In this way, the Cu-CSG organic-inorganic complexes were deposited on the cathode plate together with trapped hydrogen bubbles (Figures 1B, upper row and 2B1-B5), which made the coating porous after being air-dried (Figure 1B, lower row). In this process, $\mathrm{Cu}$ ions were reduced to metallic $\mathrm{Cu}$, which were embedded in the polymer coatings. As shown in Figure 1B, the coatings became more purple, indicating the reduction of $\mathrm{Cu}^{2+}$ ions to metallic $\mathrm{Cu}^{39}$ This speculation was also identified by the XPS result (Figure 3D), which showed the presence of metallic $\mathrm{Cu}$ in the coating of the $\mathrm{Cu}$ IV group, while the other groups did not show the peak of $\mathrm{Cu}$ probably because of the low content. In addition, the organic chitosan and gelatin in the coatings can work as stabilizers to protect metallic $\mathrm{Cu}$ against oxidation. . $^{40,41}$

$$
\begin{gathered}
\mathrm{CS}^{-N_{3}}{ }_{3}^{+}+\mathrm{OH}^{-} \rightarrow \mathrm{CS}^{-\mathrm{NH}_{2}}+\mathrm{H}_{2} \mathrm{O} \text { (cathode) } \\
\mathrm{Cu}^{2+}+2 \mathrm{e}^{-} \rightarrow \mathrm{Cu}
\end{gathered}
$$

FESEM (Figure 2Bf-Bo) demonstrated that microparticles appeared in the polymer matrix after the addition of $\mathrm{Cu}$, and its density increased as the $\mathrm{Cu}$ concentration became higher. Particularly, these microparticles were composed of smaller nanoscale structures (Figure 2Bp-Bt). Combining these with the TEM results of fresh coatings (Figure 2A), we speculated that during the drying process, nanoparticles underwent aggregation and developed into the microparticles.

All Cu-containing nanocomposite coatings presented a biphasic release of $\mathrm{Cu}$ with an initial burst release followed by sustained release (Figure 4B). The burst release profile could assure high drug concentration in the local area, whereas continuous release in the following days guaranteed the enduring effects of the functionalized coatings. These results indicated that the organic CSG coating could serve as a drug carrier enabling the enduring release of $\mathrm{Cu}$. In addition, $\mathrm{Cu}$ compounds released from the coatings displayed nanoscale structures (Figure 4C).

The study on the swelling ratio of the coatings indicated that incorporation of $\mathrm{Cu}$ with organic CSG coatings did not influence the swelling property significantly (Figure 5A). All dried coatings could swell $>10$ times after immersion in PBS solution, and recovered to three-dimensional macroporous structures. The enlargement in volume enabled the coating to fill in small gaps (gap-bridging) surrounding the substrate, which was crucial for its stabilization, ${ }^{4}$ while most inorganic coatings did not have such a property. Tensile bond strength in the substrate coating interface is another important factor affecting stabilization. In our previous study, the CSG coating 
alone could withstand interfacial stress during surgical insertion process. ${ }^{26}$ In the current study, the tensile bone strength of the CSG coating was even enhanced by the incorporation of $\mathrm{Cu}$ (Figure 5C).

Nowadays, BAI is becoming one of the major causes for implantation failure. ${ }^{42}$ On one hand, surgeons should follow strict disinfection procedures to avoid contamination. On the other, demands were made for Ti substrates with antibacterial capability. Our results demonstrated that the $\mathrm{Cu}$-containing nanocomposite coatings exhibited antibacterial activity against both $E$. coli and $S$. aureus, the most common Gram-negative and Gram-positive microbial pathogens in BAI, respectively (Figures 6-8). With the increasing $\mathrm{Cu}$ concentration in CSG coating, the antibacterial ability became more prominent. The results of the present study are in agreement with other reports that proposed the antibacterial ability of $\mathrm{Cu}$. Furthermore, $\mathrm{Cu}$ gained importance as a novel antimicrobial agent due to its strong antibacterial activity against not only traditional microorganisms but also several multidrug-resistant organisms. ${ }^{43,44}$ Compared with other metal ions (including silver, zinc, cadmium, lead), $\mathrm{Cu}$ has displayed higher antimicrobial efficacy against resistant strains under certain conditions. ${ }^{45,46}$ In addition, researchers found that $\mathrm{Cu}$ ions could destroy the permeability of bacterial membranes, promote the generation of bacterial-killing reactive oxygen species (ROS), and disturb the process of gene replication. ${ }^{14}$ In our research, similar results showed that $\mathrm{Cu}$-bearing coatings undermined the permeability of bacterial membranes, and led to the leakage of bacterial proteins (Figure 9). However, further research is needed to illustrate the exact mechanism of antibacterial ability of $\mathrm{Cu}-\mathrm{CSG}$ coatings.

It has been widely accepted that surface chemistry of biomaterials plays a decisive role in biological reactions of surrounding tissue and cells. ${ }^{47,48}$ In this study, we investigated the biocompatibility of $\mathrm{Cu}-\mathrm{CSG}$ coatings using BMSCs, which is an important cell source in bone tissue engineering. Cell proliferation tests revealed that all $\mathrm{Cu}$-doped coatings were favorable for the cell proliferation except $\mathrm{Cu}$ IV group (Figure 10B). One explanation would be that excessive $\mathrm{Cu}$ was released from $\mathrm{Cu}$ IV coatings and led to the formation of abundant hydroxyl radicals which were toxic to cells. ${ }^{49}$ Interestingly, we noticed that compared with free $\mathrm{Cu}$ ions, the $\mathrm{Cu}-\mathrm{CSG}$ group with the same $\mathrm{Cu}$ concentration in cell culture medium displayed significantly higher cell activity (Figure 10C), indicating that the cytotoxicity of the inorganic $\mathrm{Cu}$ ions was actually reduced when co-deposited with the organic CSG polymer via EPD. One possible reason for this phenomenon was that the combination of $\mathrm{Cu}$ with biocompatible chitosan could reduce its cytotoxicity by preventing the generation of ROS. ${ }^{50}$

Osteogenesis and angiogenesis are intricately linked, and osteogenesis would not be possible without angiogenesis. ${ }^{51-53}$ Many studies revealed that $\mathrm{Cu}$ could promote angiogenesis, possibly through mimicking the hypoxic microenvironment, where HIF- $1 \alpha$ and VEGF were activated to promote neovascularization and tissue regeneration. ${ }^{49,54}$ Our results demonstrated that $\mathrm{Cu}$-doped coatings induced angiogenesis-related gene expression of BMSCs in a dose-dependent manner (Figure 11). Expressions of HIF-1 $\alpha$ and VEGF in $\mathrm{Cu}$ II and $\mathrm{Cu}$ III groups were significantly elevated compared with the $\mathrm{CSG}$ group, whereas the high concentration of $\mathrm{Cu}$ in $\mathrm{Cu}$ IV group inhibited the expression. The results of ALP activity and RT-qPCR of osteogenesis-related genes showed that osteogenic differentiation of BMSCs on the $\mathrm{Cu}$-containing coatings increased steadily as $\mathrm{Cu}$ entrapment ascended, but detrimental influence was displayed in the $\mathrm{Cu}$ IV group (Figure 12). Moreover, we also found that the expression of collagen II (Col-2; typical for chondrogenesis) did not increase significantly when the coatings were incorporated with $\mathrm{Cu}$, and the expression level of Col-1 was extremely higher compared with that of Col-2 (Figure S1A and B). These results further confirmed our hypothesis that $\mathrm{Cu}-$ doped materials in our study had osteogenic activities but no chondrogenic abilities. Furthermore, $\mathrm{Cu}$-doped coatings did not affect the expression of collagen X (Figure S1C), indicating that there was no hypertrophy during the osteogenic differentiation of BMSCs. ${ }^{55}$ Therefore, our results indicated that $\mathrm{Cu}$ element in an appropriate concentration range could improve angiogenic and osteogenic activities of CSG coatings.

To determine the proper $\mathrm{Cu}$ concentration with balanced antibacterial activity and low cytotoxicity, we involved four concentrations ranging from 0.01 to $10 \mathrm{mM}$. The antibacterial activity increased as $\mathrm{Cu}$ concentration increased and peaked at $10 \mathrm{mM}$. However, at this concentration, the coating showed drastic cytotoxicity. Taking together the effects on angiogenic and osteogenic genes expression, we believe that a $\mathrm{Cu}$ concentration around $1 \mathrm{mM}$ will guarantee considerable antibacterial activity and benefit angiogenic and osteogenic differentiation while cell activity is not greatly disturbed.

\section{Conclusion}

For the first time, we successfully synthesized a $\mathrm{Cu}$-doped organic-inorganic CSG coating on Ti substrate using green EPD technique. The obtained $\mathrm{Cu}-\mathrm{CSG}$ nanocomposite 
coating, which is a gap-bridging coating with low cytotoxicity, was demonstrated to possess antibacterial, angiogenic, and osteogenic properties. Overall, the $\mathrm{Cu}-\mathrm{CSG}$ coating showed great potential for improving the biological performance of Ti-based materials, although in vivo evaluation is necessary for further research.

\section{Acknowledgments}

This study was supported by the National Natural Science Foundation of China (no 81371170, 81470771, and 81571011) and the Fundamental Research Funds for the Central Universities (no 2042017kf0075).

\section{Author contributions}

All authors contributed toward data analysis, drafting and revising the paper and agree to be accountable for all aspects of the work.

\section{Disclosure}

The authors report no conflicts of interest in this work.

\section{References}

1. Ödman J, Lekholm U, Jemt T, Brånemark PI, Thilander B. Osseointegrated titanium implants - a new approach in orthodontic treatment. Eur J Orthod. 1988;10(2):98-105.

2. Geetha M, Singh AK, Asokamani R, Gogia AK. Ti based biomaterials, the ultimate choice for orthopaedic implants - a review. Prog Mater Sci. 2009;54(3):397-425.

3. Liu X, Chu PK, Ding C. Surface modification of titanium, titanium alloys, and related materials for biomedical applications. Mater Sci Eng R Rep. 2003;47(3-4):49-121.

4. Raphel J, Holodniy M, Goodman SB, Heilshorn SC. Multifunctional coatings to simultaneously promote osseointegration and prevent infection of orthopaedic implants. Biomaterials. 2016;84:301-314.

5. Gristina AG. Biomaterial-centered infection: microbial adhesion versus tissue integration. Science. 1987;237(4822):1588-1595.

6. Stigter M, Bezemer J, Groot KD, Layrolle P. Incorporation of different antibiotics into carbonated hydroxyapatite coatings on titanium implants, release and antibiotic efficacy. J Control Release. 2004;99(1): 127-137.

7. Wu C, Chang J. Multifunctional mesoporous bioactive glasses for effective delivery of therapeutic ions and drug/growth factors. J Control Release. 2014;193:282-295.

8. Schliephake H, Rublack J, Förster A, Schwenzer B, Reichert J, Scharnweber D. Functionalization of titanium implants using a modular system for binding and release of VEGF enhances bone-implant contact in a rodent model. J Clin Periodontol. 2015;42(3):302-310.

9. Campoccia D, Montanaro L, Speziale P, Arciola CR. Antibiotic-loaded biomaterials and the risks for the spread of antibiotic resistance following their prophylactic and therapeutic clinical use. Biomaterials. 2010; 31(25):6363-6377.

10. Mouriño V, Cattalini JP, Boccaccini AR. Metallic ions as therapeutic agents in tissue engineering scaffolds: an overview of their biological applications and strategies for new developments. $J R$ Soc Interface. 2011;9(68):401-419.

11. Ren N, Li J, Qiu J, et al. Nanostructured titanate with different metal ions on the surface of metallic titanium: a facile approach for regulation of rBMSCs fate on titanium implants. Small. 2014;10(15):3169-3180.
12. Kim HS, Kim YJ, Jang JH, Park JW. Surface engineering of nanostructured titanium implants with bioactive ions. J Dent Res. 2016; 95(5):558-565.

13. Heidenau F, Mittelmeier W, Detsch R, et al. A novel antibacterial titania coating: metal ion toxicity and in vitro surface colonization. J Mater Sci Mater Med. 2005;16(10):883-888.

14. Li M, Ma Z, Zhu Y, et al. Toward a molecular understanding of the antibacterial mechanism of copper-bearing titanium alloys against Staphylococcus aureus. Adv Healthcare Mater. 2016;5(5):557-566.

15. Wang H, Zhao S, Zhou J, et al. Evaluation of borate bioactive glass scaffolds as a controlled delivery system for copper ions in stimulating osteogenesis and angiogenesis in bone healing. J Mater Chem B. 2014; 2(48):8547-8557.

16. Yu L, Jin G, Ouyang L, Wang D, Qiao Y, Liu X. Antibacterial activity, osteogenic and angiogenic behaviors of copper-bearing titanium synthesized by PIII\&D. J Mater Chem B. 2016;4(7):1296-1309.

17. Wu Q, Li J, Zhang W, et al. Antibacterial property, angiogenic and osteogenic activity of $\mathrm{Cu}$-incorporated $\mathrm{TiO}_{2}$ coating. J Mater Chem B. 2014;2(39):6738-6748.

18. Wu C, Zhou Y, Xu M, et al. Copper-containing mesoporous bioactive glass scaffolds with multifunctional properties of angiogenesis capacity, osteostimulation and antibacterial activity. Biomaterials. 2013; 34(2):422-433.

19. Zheng K, Dai X, Lu M, Hüser N, Taccardi N, Boccaccini AR. Synthesis of copper-containing bioactive glass nanoparticles using a modified Stöber method for biomedical applications. Collids Surf B Biointerfaces. 2016;150(2017):159-167

20. Burghardt I, Lüthen F, Prinz C, et al. A dual function of copper in designing regenerative implants. Biomaterials. 2015;44(44):36-44.

21. Zhao L, Wang H, Huo K, et al. The osteogenic activity of strontium loaded titania nanotube arrays on titanium substrates. Biomaterials. 2013;34(1):19-29.

22. Andersen OZ, Offermanns V, Sillassen M, et al. Accelerated bone ingrowth by local delivery of strontium from surface functionalized titanium implants. Biomaterials. 2013;34(24):5883-5890.

23. Besra L, Liu M. A review on fundamentals and applications of electrophoretic deposition (EPD). Prog Mater Sci. 2007;52(1):1-61.

24. Song J, Chen Q, Zhang Y, et al. Electrophoretic deposition of chitosan coatings modified with gelatin nanospheres to tune the release of antibiotics. ACS Appl Mater Interfaces. 2016;8(22):13785-13792.

25. Jiang T, Zhang Z, Zhou Y, et al. Surface functionalization of titanium with chitosan/gelatin via electrophoretic deposition: characterization and cell behavior. Biomacromolecules. 2010;11(5):1254-1260.

26. Ma K, Cai X, Zhou Y, Zhang Z, Jiang T, Wang Y. Osteogenetic property of a biodegradable three-dimensional macroporous hydrogel coating on titanium implants fabricated via EPD. Biomed Mater. 2014; 9(1):015008.

27. Cai X, Ma K, Zhou Y, Jiang T, Wang Y. Surface functionalization of titanium with tetracycline loaded chitosan-gelatin nanosphere coatings via EPD: fabrication, characterization and mechanism. RSC Adv. 2016;6(9):7674-7682.

28. Ma K, Dan H, Jing C, et al. Surface functionalization with strontiumcontaining nanocomposite coatings via EPD. Collids Surf B Biointerfaces. 2016;146:97-106.

29. Tokarek K, Hueso JL, Kutrowski P, Stochel G, Kyzio A. Green synthesis of chitosan-stabilized copper nanoparticles. Eur J Inorg Chem. 2013;2013(28):4940-4947.

30. Thekkae Padil VV, Černik M. Green synthesis of copper oxide nanoparticles using gum karaya as a biotemplate and their antibacterial application. Int J Nanomedicine. 2013;8(8):889-898.

31. Iravani S. Green synthesis of metal nanoparticles using plants. Green Chem. 2011;13(10):2638-2650.

32. Zhang Z, Jiang T, Ma K, Cai X, Zhou Y, Wang Y. Low temperature electrophoretic deposition of porous chitosan/silk fibroin composite coating for titanium biofunctionalization. J Mater Chem. 2011;21(21): $7705-7713$ 
33. Zhao L, Wang H, Huo K, et al. Antibacterial nano-structured titania coating incorporated with silver nanoparticles. Biomaterials. 2011; 32(24):5706-5716.

34. Manjubala I, Scheler S, Bössert J, Jandt KD. Mineralisation of chitosan scaffolds with nano-apatite formation by double diffusion technique. Acta Biomater. 2006;2(1):75-84.

35. Hong S, Hu X, Fei Y, Bei J, Wang S. Combining oxygen plasma treatment with anchorage of cationized gelatin for enhancing cell affinity of poly(lactide-co-glycolide). Biomaterials. 2007;28(29): 4219-4230.

36. Sorlier $\mathrm{P}$, Denuzière $\mathrm{A}$, Viton $\mathrm{C}$, Domard $\mathrm{A}$. Relation between the degree of acetylation and the electrostatic properties of chitin and chitosan. Biomacromolecules. 2001;2(3):765-772.

37. Guibal E. Interactions of metal ions with chitosan-based sorbents: a review. Sep Purif Technol. 2004;38(1):43-74.

38. Cheng Y, Luo X, Betz J, et al. In situ quantitative visualization and characterization of chitosan electrodeposition with paired sidewall electrodes. Soft Matter. 2010;6(14):3177-3183.

39. Patel A, Shukla P, Rufford T, et al. Catalytic reduction of NO by CO over copper-oxide supported mesoporous silica. Appl Catal A Gen. 2011;409(23):55-65.

40. Usman MS, El Zowalaty ME, Shameli K, Zainuddin N, Salama M, Ibrahim NA. Synthesis, characterization, and antimicrobial properties of copper nanoparticles. Int J Nanomedicine. 2013;8(1): 4467-4479.

41. Chatterjee AK, Sarkar RK, Chattopadhyay AP, Aich P, Chakraborty R, Basu T. A simple robust method for synthesis of metallic copper nanoparticles of high antibacterial potency against E. coli. Nanotechnology. 2012;23(8):85103-85113.

42. Busscher HJ, van der Mei HC, Subbiahdoss G, et al. Biomaterialassociated infection: locating the finish line in the race for the surface. Sci Transl Med. 2012;4(153):2569-2575.

43. Paladini F, Pollini M, Sannino A, Ambrosio L. Metal-based antibacterial substrates for biomedical applications. Biomacromolecules. 2015; 16(7):1873-1885.

44. Grass G, Rensing C, Solioz M. Metallic copper as an antimicrobial surface. Appl Environ Microbiol. 2011;77(5):1541-1547.
45. Michels HT, Noyce JO, Keevil CW. Effects of temperature and humidity on the efficacy of methicillin-resistant Staphylococcus aureus challenged antimicrobial materials containing silver and copper. Lett Appl Microbiol. 2009;49(2):191-195.

46. Chudobova D, Dostalova S, Ruttkay-Nedecky B, et al. The effect of metal ions on Staphylococcus aureus revealed by biochemical and mass spectrometric analyses. Microbiol Res. 2015;170(4687):147-156.

47. Fernandezyague MA, Abbah SA, Mcnamara L, Zeugolis DI, Pandit A, Biggs MJ. Biomimetic approaches in bone tissue engineering: integrating biological and physicomechanical strategies. Adv Drug Deliv Rev. 2015;84:1-29.

48. Yang X, Wang D, Liang Y, et al. A new implant with solid core and porous surface: the biocompatability with bone. J Biomed Mater Res A. 2014;102(7):2395-2407.

49. Martin F, Linden T, Katschinski DM, et al. Copper-dependent activation of hypoxia-inducible factor (HIF)-1: implications for ceruloplasmin regulation. Blood. 2005;105(12):4613-4619.

50. Worthington KL, Adamcakovadodd A, Wongrakpanich A, et al. Chitosan coating of copper nanoparticles reduces in vitro toxicity and increases inflammation in the lung. Nanotechnology. 2013;24(39):395101.

51. Carano RAD, Filvaroff EH. Angiogenesis and bone repair. Drug Discov Today. 2003;8(21):980-989.

52. Bose S, Fielding G, Tarafder S, Bandyopadhyay A. Understanding of dopant-induced osteogenesis and angiogenesis in calcium phosphate ceramics. Trends Biotechnol. 2013;31(10):594-605.

53. Riddle RC, Khatri R, Schipani E, Clemens TL. Role of hypoxiainducible factor- $1 \alpha$ in angiogenic-osteogenic coupling. $\mathrm{J} \mathrm{Mol} \mathrm{Med}$ (Berl). 2009;87(6):583-590.

54. Weidemann A, Johnson RS. Biology of HIF-1alpha. Cell Death Differ. 2008;15(4):621-627.

55. Pelttari K, Winter A, Steck E, et al. Premature induction of hypertrophy during in vitro chondrogenesis of human mesenchymal stem cells correlates with calcification and vascular invasion after ectopic transplantation in SCID mice. Arthritis Rheum. 2006;54(10):3254-3266. 


\section{Supplementary material}
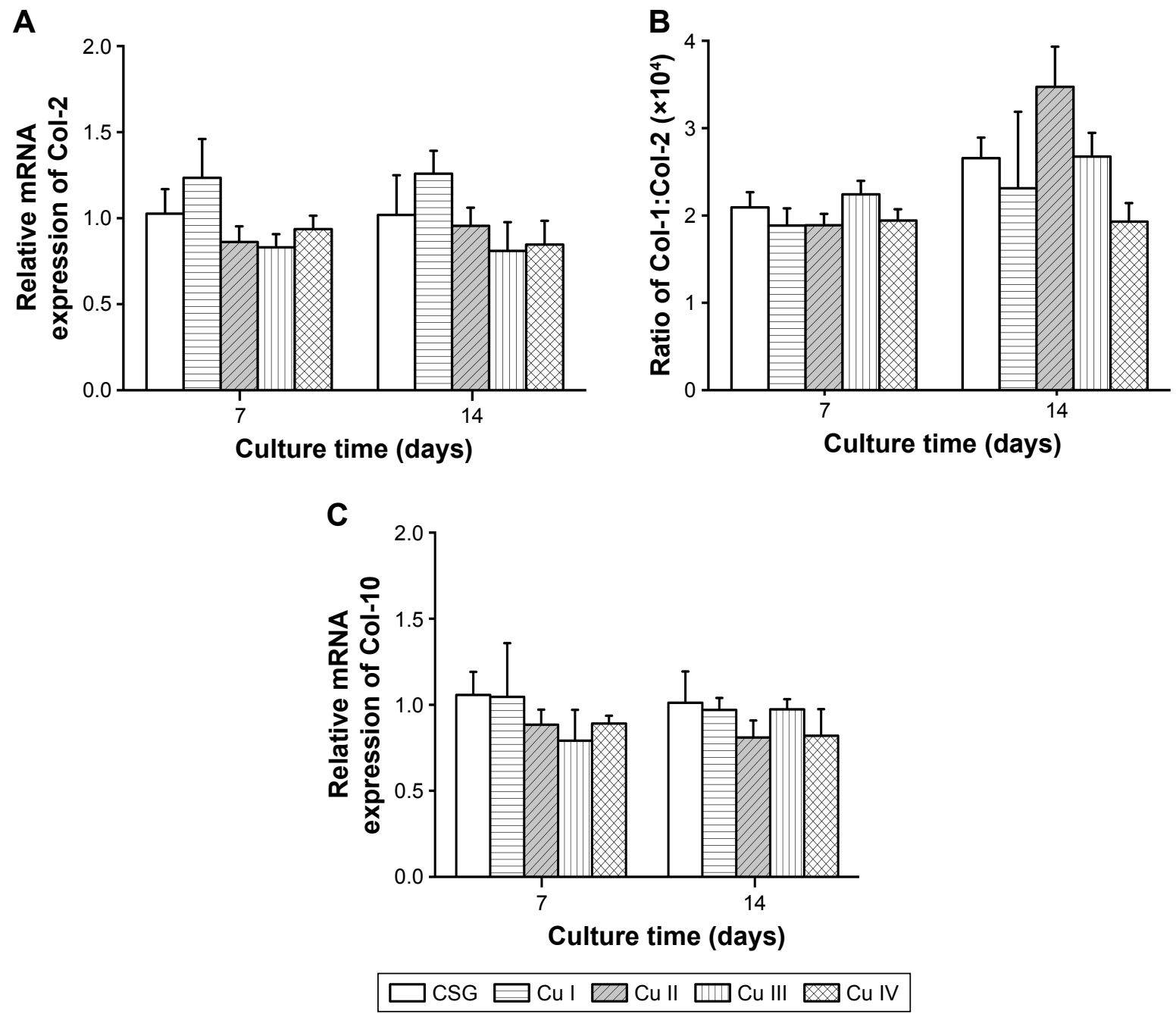

Figure SI (A) Gene expression level of collagen II, (B) ratio of collagen I:collagen II, and (C) collagen X in BMSCs cultured with various samples at specific time intervals. Notes: $\mathrm{n}=3$; no significant differences were found between the CSG group and copper-containing groups.

Abbreviations: CSG, chitosan-gelatin; Col-I, collagen I; Col-2, collagen II; Col-10, collagen X; BMSCs, bone marrow stromal cells.

\section{Publish your work in this journal}

The International Journal of Nanomedicine is an international, peerreviewed journal focusing on the application of nanotechnology in diagnostics, therapeutics, and drug delivery systems throughout the biomedical field. This journal is indexed on PubMed Central, MedLine, CAS, SciSearch $®$, Current Contents ${ }^{\circledR} /$ Clinical Medicine,
Journal Citation Reports/Science Edition, EMBase, Scopus and the Elsevier Bibliographic databases. The manuscript management system is completely online and includes a very quick and fair peer-review system, which is all easy to use. Visit http://www.dovepress.com/ testimonials.php to read real quotes from published authors. 